Review Article

\title{
Biodiversity, the Human Microbiome and Mental Health: Moving toward a New Clinical Ecology for the 21st Century?
}

\author{
Susan L. Prescott, ${ }^{1}$ Rachel A. Millstein, ${ }^{2}$ Martin A. Katzman, ${ }^{3}$ and Alan C. Logan ${ }^{4}$ \\ ${ }^{1}$ School of Paediatrics and Child Health Research, University of Western Australia, Princess Margaret Hospital, P.O. Box D184, \\ Perth, WA 6001, Australia \\ ${ }^{2}$ Department of Psychiatry, Massachusetts General Hospital, Harvard Medical School, Boston, MA 02114, USA \\ ${ }^{3}$ Department of Psychiatry, Faculty of Medicine, University of Toronto, Toronto, ON, Canada M5T 1R8 \\ ${ }^{4}$ CAMNR, 23679 Calabasas Road, Suite 542, Calabasas, CA 91302, USA
}

Correspondence should be addressed to Susan L. Prescott; susan.prescott@uwa.edu.au

Received 17 April 2016; Accepted 30 May 2016

Academic Editor: Alexandre Rosado

Copyright ( 2016 Susan L. Prescott et al. This is an open access article distributed under the Creative Commons Attribution License, which permits unrestricted use, distribution, and reproduction in any medium, provided the original work is properly cited.

\begin{abstract}
Advances in research concerning the brain-related influences of the microbiome have been paradigm shifting, although at an early stage, clinical research involving beneficial microbes lends credence to the notion that the microbiome may be an important target in supporting mental health (defined here along the continuum between quality of life and the criteria for specific disorders). Through metagenomics, proteomics, metabolomics, and systems biology, a new emphasis to personalized medicine is on the horizon. Humans can now be viewed as multispecies organisms operating within an ecological theatre; it is important that clinicians increasingly see their patients in this context. Historically marginalized ecological aspects of health are destined to become an important consideration in the new frontiers of practicing medicine with the microbiome in mind. Emerging evidence indicates that macrobiodiversity in the external environment can influence mental well-being. Local biodiversity may also drive differences in human-associated microbiota; microbial diversity as a product of external biodiversity may have far-reaching effects on immune function and mood. With a focus on the microbiome as it pertains to mental health, we define environmental "grey space" and emphasize a new frontier involving bio-eco-psychological medicine. Within this concept the ecological terrain can link dysbiotic lifestyles and biodiversity on the grand scale to the local human-associated microbial ecosystems that might otherwise seem far removed from one another.
\end{abstract}

\section{Introduction}

From the perspective of clinical medicine, it is at once both fascinating and daunting to consider the implications of rapidly unfolding research under the broad term of microbial ecology. It is now evident that animal life cannot be viewed as functionally separate to the organisms that live in symbiosis with it $[1,2]$. Rather, life can be viewed through the lens of the holobiont, that is, the multicellular eukaryote and the inseparable colonies of persistent symbionts which together form a critically important unit of anatomy, physiology, immunology, growth, and evolution. At the very least, the host plus its microbiome (microbiota and their collective genomes) can be regarded as an ecological community [3].
To give perspective to this profound contemporary shift in biological thinking, we need to only consider that the protein-coding genes derived from Homo sapiens are far short of the totality of DNA on and within the body. Much of this genetic differential is accounted for by the sizeable gene contributions of microorganisms [4]. Importantly, these microbial genetic contributions are functional and include activities that influence nutrient absorption, protection against pathogens, maintenance of barriers to the outside environment, and the manufacture of chemicals necessary for survival. Microbial contributions also extend to functional interactions with environmental chemicals (xenobiotics) [5].

Advances in microbial identification have cast light on complex ecosystems in cutaneous, gastrointestinal (GI), oral, 
respiratory, vaginal, and other anatomical locations [6]. There is a greater appreciation of the functional relationships within this ecological theatre, that is, the ways in which specific microbes (and the overall microbiome) influence, and are influenced by, human health and disease. This allows optimism that translation of this knowledge will give greater emphasis to prevention and transform personalized clinical medicine [7]. Possibilities in this optimistic view include the idea that "targeting the microbiome" might be clinically relevant to mental health [8].

With this background, it is logical that the biological elements within the biopsychosocial paradigm (the simultaneous attendance to biological, psychological, and social dimensions of illness [9]) will take center stage in this new era. For the most part, the microbiome therapeutics, at least from the dominant biomedical model, translates into the promise of microbe-based biotechnical interventions (or agents that directly/indirectly influence microbes) [10, 11]. There is undeniable promise in these translation efforts.

However, it is our contention that oft-overlooked environmental factors which push against microbial diversity, including those that are a product of modernity as described in detail later, are also vital to the success of its future biotechnical interventions. This, we argue, is especially true in complex mental disorders. If we accept the holobiont view that humans are multispecies organisms, then we must also accept that we operate within an ecological theatre. That is, we are not disconnected, clinically, from larger aspects of ecology.

Our aim here is to provide an interdisciplinary vantage point from which these envisioned near-future clinical approaches can be viewed in the larger contexts of biodiversity and ecosystems. The essentiality of global biodiversity, the variety of species, their genetic contribution, and the ecosystems they form, for human health and well-being, including mental health, is unequivocal $[12,13]$. However, the topic of biodiversity and ecosystems can be set into silos that seem far removed from clinical relevancy. Advances in the study of the microbiome (a topic that exemplifies discussions of diversity and ecosystems) have unified disciplines and are shedding light on why biodiversity matters to healthcare [14].

Using mental health as a surrogate of total human health, we define a bio-eco-psychological perspective to underscore that clinical discussions of cutaneous and/or gut microbial ecosystems are also connected to external environments. As with ecosystems on the grand scale, the available evidence indicates that diverse microbial ecosystems in human niches are associated with states of health. We argue that ecological aspects of health are now poised to become an important consideration in the new frontiers of medicine with the microbiome in mind.

Our focus on mental health is based on its relevancy to virtually every aspect of clinical and public health medicine. As the World Health Organization (WHO) appropriately states, there is "No Health without Mental Health," and conversely, mental health is often compromised in the absence of physical health [15]. The bidirectional linkage between mental disorders and noncommunicable diseases has been the subject of volumes of research.

\section{Microbiota and the Table of Health}

The history of the genus Homo is a story of coevolution with microbes. For some 3 million years, commensal microbes have established their ecological niches on and within us. The Latin roots of the term "commensal" (com, together; mensa, table) underscore the fact that we eat at the same table, as a family and without injury. Commensal is thus defined elegantly in a 19th century dictionary: term used in regard to an animal living like the messmate of another, that is, sharing the food of his host without being parasitic upon him [17]. Later, we will discuss the potentially injurious ways in which westernization has changed what we and our messmates, commensal microbes, actually "eat."

First, and to more fully appreciate how microbiota of modernity may compromise evolutionary-rooted immune functioning, it is important to briefly review how and in what ways microbiota contributes to health under normal circumstances. These benefits may be described as ecosystem services; in addition to the "education" of the immune system, they include, but are not limited to, protection against pathogens, maintenance of barriers to the external environment (e.g., cutaneous structures and intestinal mucosa), nutrient extraction, production of vitamins, transformation of dietary phytochemicals, lipid metabolism, provision of short chain fatty acid, and a host of other potentially bioactive metabolites, as well as the metabolism of xenobiotics $[18,19]$.

The critical role of commensal microbes in health has been gleaned by observing the consequences of disturbing normal microbial ecosystems (e.g., through antimicrobial use, dietary changes (discussed in more detail later)). Dysbiosis is defined technically as "difficult living" or "life in distress"; given biodiversity losses, climate change, rapid urbanization, and other threats to ecosystems, it has been argued that dysbiosis is an apt descriptive at the global level [20]. However, dysbiosis is most commonly used as a single word to define disruptions to the structure of complex commensal microbial communities. Generally, the perturbations involve at least one or a combination of the following: loss of beneficial microorganisms and/or the expansion of potentially harmful microbes and/or the loss of overall microbial diversity [21]. Beyond manipulated dysbiosis, remarkable studies involving germ-free (GF) and specific-pathogen-free (SPF) animals have long since demonstrated that microbial colonization and diverse ecosystems can influence the immune system, behavior, and even neurotransmitter availability in the brain [22-24]. GF models allow for evaluations of the introduction of single or multispecies of bacterium, and the use of germ-free mice with specific genetic traits facilitates gene and microbe evaluations. SPF models include commensal bacteria but are absent known pathogens that could otherwise cause overt or subsyndromal infections [25].

\section{Normal Contours and Abnormal Drifts of the Microbiome}

Emerging research is illuminating the ways in which the gut microbiome is established. There is little doubt that the shaping of the microbiome in early life, and the ways in which this 
shaping may be influenced by stress (to be discussed later), dietary patterns, antibiotic exposure, and other ecological factors, is an epic story that may influence NCD risk over the life course [20]. The rapidly expanding research under the developmental origins of health and disease (DOHaD) rubric demonstrates the long-term consequences of these early life environmental exposures.

The long-held dogma that (notwithstanding specific infection or inflammation) human fetuses are contained in a sterile environment has recently been challenged. It is evident that bacterial exposure across the placental barrier is possible, likely via gut epithelium translocation, oral microabrasions leading to systemic microbial access, or other undetermined pathways $[26,27]$. Researchers are now examining the ways in which this ultra-early microbial exposure might influence pregnancy outcomes and subsequent immune responses [20].

Through the first 1000 days of life outside the womb, the stability and diversity of intestinal microbiota are increased [26], taking on an adult-like community structure. However, there are distinct compositional and functional characteristics to the preadolescent gut microbiome, and these reflect a supportive role in rapid growth and development [28]. Gestational age (preterm versus term), antibiotic exposure, delivery mode (vaginal versus caesarean-section), breast versus formula feeding, introduction of solid foods (and types of foods), and genetics can influence microbial colonization.

Four primary phyla-Actinobacteria, Proteobacteria, Firmicutes, and Bacteroidetes-and several hundred species (per person, per fecal sample [29]) help define the adult intestinal ecosystem. Firmicutes and Bacteroidetes reign numerically within the phyla, and early evidence suggests that an expansion of Proteobacteria may be an indicator of dysbiosis. On the other hand, genus-level Bacteroides and Prevotella may reflect a healthier state $[30,31]$.

There are other indications that certain microbes may emerge as early life indicators of long-term risk to health. For example, the relative abundance of the bacterial genera Lachnospira, Veillonella, Faecalibacterium, and Rothia during the first three months of life has been linked to a decreased risk of subsequent asthma. Evidence of causation is inferred when these microbes are supplemented in a germ-free animal model to demonstrate reduction in airway inflammation in adult offspring. However, there may be critical windows in early life where these microbial differences (i.e., those related to subsequent risk) are apparent [32]. With immune priming via microbes, these windows may also exist for mental health outcomes.

Although it remains unclear what constitutes an ideal gut (or other niche) microbial composition, there are now many studies pointing toward altered gut microbiota as a possible contributor to many, if not most, NCDs. Proof of causation remains elusive. However, the idea that an altered microbiota (or microbiome) may be a "transducer" organ responsible for signaling low-grade inflammation and metabolic dysregulation is well supported in animal models $[33,34]$.

Asthma and depression do not occur randomly in populations and are instead associated with socioeconomic disadvantage. Along with allergic diseases in general, they are linked to epidemiological transitions $[35,36]$. Thus, the preclinical research forces some questions: what lifestyle factors might be pushing alterations in human-associated microbial ecosystems and diminished gut bacterial gene richness? Are the risks of altered microbiota equal among all socioeconomic groups, or are they slanted to more vulnerable populations? How can we prevent alterations to microbial ecosystems from happening in the first place?

\section{Dietary Patterns, Hygiene, and Dysbiotic Drift}

Research concerning epidemiological transitions and westernization (accompanied by expansion of highly processed foods, fast-food availability, circadian disruptions, lowered physical activity, and other lifestyle variables) indicates that other NCDs including mental disorders will follow the global trends witnessed in allergic diseases [37, 38]. Adherence to healthy, traditional dietary patterns such as the Mediterranean diet can lead to important shifts in intestinal microbiota and higher fecal short chain fatty acid (SCFA) production [39]. In addition to nutrient-induced influences, diminished food processing associated with traditional diets (local, farm-to-table) may place the consumer in contact with the estimated $35 \%$ of all lactic acid bacteria isolated from raw fruits and vegetables that can survive gastric conditions [40]. This may help explain the connection between such dietary patterns and reduced risk (or conversely, increased risk with highly processed foods) of depression, asthma, allergies, and other NCDs [41-43].

The future relevancy of ecosystems in the clinic is evidenced by the findings that even short-term dietary changes can influence genus and species level microbes [44, 45]. Research shows significant increases in bacterial gene richness after increased consumption of fruits, vegetables, and dietary fiber; this highlights that diet influences microbial function and, hence, host-microbe relations [46, 47]. Support for the functional importance of bacterial gene richness is evident in its association with reduced risk of NCDs and biomarkers of chronic disease such as insulin resistance and lipidemia [48].

The turn from traditional lifestyles and adoption of westernization are not a zero-sum game. There is a continuum whereby there is an absence of traditional early life exposures that could otherwise work toward proper immunemicrobiota relations (i.e., immune system education and long-lasting epigenetic influences) [49] and the presence of detrimental exposures that contribute to what has been referred to as "dysbiotic drift" (i.e., a product of the cumulative environmental forces in westernized nations, particularly factors most confronted by vulnerable populations) [16] Indeed, recent research from North America demonstrates reduced diversity of colonic microbiota (sampled via mucosal biopsy) among residents of lower socioeconomic status (SES) neighborhoods [50]. As expected, an opposite pattern can occur in developing nations where lower SES is associated with microbial diversity as it may represent adherence to more traditional lifestyle activities [51]. 
The hygiene hypothesis and its variants have traditionally focused on missing microbial exposures due to smaller family sizes, sanitation, and antimicrobial use [52]. The dysbiotic drift theory expands upon this and focuses on a slant whereby environmental contaminants, high-fat diets, food additives, advanced glycation end-products, sedentary behavior, circadian disruptions, and other aspects of westernized lifestyles place a heavier burden on socioeconomically disadvantaged populations. Both hygiene and the westernized lifestyle drift very likely work toward clinically relevant alterations in microbial ecology. However, as we will discuss shortly, changes in exposure or inequitable access to natural environments may also be a relevant factor.

It is difficult to discuss dysbiosis in the context of NCDs without bringing into the discourse the massive rise in global production, transport, and consumption of highly processed foods [53]. Available animal and human research shows that lack of fiber and phytochemicals and the presence of high sugar/refined fat may represent a significant threat to microbial diversity [54]. The loss of microbial diversity as a result of adoption of westernized dietary practices may even extend over generations [55]. It is therefore possible to theorize that dysbiosis is occurring at the individual and community level and that the commercial forces (and absence of policy) which drive a highly processed diet and a "dysbiosis by default" should be part of public health discourse (Figure 2).

\section{Stress, Microbes, and the Host}

Recent human studies have supported the idea that psychological stress can contribute to dysbiosis [56, 57]. In a recent study, infants delivered by mothers with high cumulative stress (i.e., high reported stress and high cortisol concentrations during pregnancy) had significantly higher relative abundances of proteobacterial groups and lower relative abundances of lactic acid bacteria (i.e., Lactobacillus, Lactococcus, and Aerococcus) and Bifidobacteria. This pattern was associated with infant health complaints [58]. There are independent associations between prenatal (maternal) depressive and anxiety symptoms and subsequent signs of allergic disease among infants [59]; therefore, a stressmicrobe-immune pathway to broad health complaints is highly plausible.

There are many acute and chronic ways in which stress could cause dysbiosis. For example, psychological stress can alter gastric secretions, motility, and other aspects of gastrointestinal physiology [60]. Stress can also lead to shifts in dietary patterns [61]. A turn to more highly processed foods (yet highly palatable; sometimes referred to as "comfort foods") may attenuate stress $[62,63]$; however, they may also cause dysbiosis [64].

In addition, there are suggestions that dysbiosis can be mediated directly by stress hormones. For example, in experimental research the increased growth of commensal and pathogenic Escherichia coli (E. coli) can exceed 10,000fold in the presence of norepinephrine and the ability of gut microbiota to adhere to mucosal surfaces can also be influenced by the hormonal cascade of sympathetic outflow [65].
Research is now shifting to the differential effects of stress on luminal versus intestinal mucosa-associated microbes [66] and neuroepithelial communication as a regulator of interactions between the intestinal mucosa and luminal bacteria [67].

Just as there are bidirectional relationships between the abilities of low-grade inflammation to provoke mood disturbances (and vice versa), emerging research shows that immune disturbances/inflammation influence dysbiosis and vice versa $[68,69]$. This is the central tenet to the inescapable notion that ecology will become relevant in clinic. In experimental research, horizons are moving beyond the mere documentation of psychosocial stress-induced dysbiosis. Through the use of computational approaches, researchers are now attempting to determine what the functional consequences of the disturbances might be, especially in the context of the metagenome [70]. Further discussions of stress and the immune-mood consequences of dysbiosis are presented below.

\section{Moving from Biopsychosocial to Bio-Eco-Psychological}

With the discovery of remarkable psychopharmacological agents (1949-1960) [71], discussions of depression (and other mental disorders) as caused by biochemical disturbances began to take center stage [72], and with scientific advances the once dominant Freudian concepts were more easily dismissed as pseudoscientific nonsense [73]. However, even early proponents of psychopharmacology warned colleagues "that there is more to psychopharmacology than the use of an adequate drug for the specific nosologic entity. There is a world of interaction, not only at the patient-doctor level, but in multiple facets of life itself," stating further that "we believe that the individual should be considered a definite biopsychosocial entity, and all aspects of this entity should be analyzed in a specific problem" [74].

Peptic ulcer-once thought to be exclusively driven by stress, anxiety, and mood states-provides a snapshot of the complexity of microbe-host interactions and an illustrative example of the broader arguments we will later make concerning the clinical relevancy of ecosystems. In an early signpost to the microbiome revolution that would unfold decades later, it was proven in the 1980s that the microorganism Helicobacter pylori, and not stress, is the causative agent in most cases of peptic ulcer [75]. In a remarkable twist, the influence of $H$. pylori on disease does not begin and end with ulcer; H. pylori (presence or, indeed, lack of exposure thereof) is now implicated in many of noncommunicable diseases (NCDs) that were at one time considered to be psychosomatic (including, but not limited to, migraine, diabetes, rheumatoid arthritis, autoimmune, and asthma/allergic diseases) [76-79].

In further support of our central tenet that clinical medicine will increasingly concern itself with microbial ecosystems, the direction of association between $H$. pylori and disease is not always toward its presence as being pathogenic. It is clear that Helicobacter pathogenicity is strain dependent. The eradication of $H$. pylori and lack of exposure 
in early life may actually take away a layer of protection against subsequent development of NCDs such as asthma and atopic disease $[80,81]$. As we will discuss later, $H$. pylori may be but one surrogate marker of the seemingly rapid change in relationships between modernized humans and their microbial ecosystems.

As with many aspects of clinical medicine, especially those that involve microbes, the story of $H$. pylori and ulcer is also complicated by the questions surrounding host vulnerability, which translates back to the psychoecological interacting with the biological [82]. While H. pylori is a provocateur of duodenal ulcer, why is it that every human carrier of the microorganism, that is, more than $50 \%$ of us, does not succumb to ulcer? How might psychosocial and, perhaps more importantly, ecological factors alter the terrain and influence virulence? Furthermore, what are the consequences of attempting to eradicate a microbe that has coevolved with humans in a generally peaceful manner [83]? What are the consequences of loss of contact with other microbes with which humans coevolved [84]?

It becomes difficult to answer these questions through the vantage point of a strictly biomedical model. Moreover, as we will argue in more detail later, lack of reference to ecology ("eco" from Greek roots oĩkoc; oikos; house/dwelling place) in the term biopsychosocial diminishes the importance of the larger environment and ecosystems relevant to human health. The intestinal, cutaneous (and other) microbial ecosystems that may be targeted in clinic are not detached from the microbes encountered (and manipulated) by the lifestyles of patients. They are a product of the activities within the larger "dwelling place." We will propose that the relationship between the microbiome and mental health, and its future clinical therapeutics, can only be truly understood through a bio-eco-psychological lens.

\section{Microbiota and Mental Health: Preclinical}

In 2004 a Japanese group reported that gene expression levels of brain derived neurotrophic factor (BDNF) were lower in the hippocampus and the brain cortex of germfree (GF) animals versus specific-pathogen-free animals. The study also showed that GF mice had enhanced hypothalamicpituitary-adrenal (HPA) axis activity following acute stress. Importantly, the exaggerated HPA stress response in GF mice was reversed by reconstitution with the beneficial microbe Bifidobacterium infantis. Thus, it demonstrated that normal commensal microbes are influencing brain structure and function that microbiota are involved in programming the stress response and that, in certain situations, a single strain of beneficial bacteria might have far-reaching effects in early life [85].

Over the last several years, volumes of international studies using rodents and various experimental approaches have established essential foundational research to support the idea that microbes matter to mental health. The collective body of preclinical work has been the subject of many detailed reviews [86, 87]. Mechanistic pathways whereby commensal (or beneficial microbe application) could potentially influence mood and fatigue were originally presented over a decade ago $[88,89]$. These are outlined in Figure 1.

At least one direct pathway between gut and brain communication via microbes has been identified as the vagus nerve; on the one hand, this pathway can promote anxious behavior among animals following even minor exposure to pathogenic microbes or induced intestinal inflammation. On the other hand, the vagus nerve can facilitate anxiolysis following supplementation with beneficial microbes [90, 91]. Yet, there are other pathways too; although extinguishing vagal communication can negate the gut-brain benefits of beneficial microbes in certain situations, there is also evidence that probiotics can positively influence behavior independent of vagotomy $[92,93]$.

Rodent GF models demonstrate that the manipulation of microbiota can impact rodent anxiety- and depression-like behavior. For example, when GF BALB/c mice are colonized with microbiota derived from NIH Swiss mice, behavioral changes are noted. In BALB/c mice the changes include a wider range of exploration and signs of increased risk taking. Ordinarily, BALB/c are less likely to explore and take risks in comparison with normal NIH Swiss mice. Reverse behavioral outcomes were also noted, displays of apprehension, when $\mathrm{NIH}$ Swiss mice were colonized with the BALB/c microbiota [94].

Separate studies involving fecal transfer demonstrate the importance of diet at the bio-psycho-ecological interface. For example, when the fecal material from mice raised on a high-fat diet was transferred to healthy, normal weight mice, the recipient animals displayed cognitive deficits and signs of anxious, stereotypical, and repetitive behavior [95]. On the other hand, systemic nutritional status, including tissue levels of essential fatty acids, can influence the production of intestinal alkaline phosphatase (IAP); this enzyme can control microbial diversity, lipopolysaccharide production, and gut permeability [96]. Indeed, many of the experimental benefits of probiotics in the context of brain and behavior may be mediated by their ability to attenuate intestinal permeability (IP) [97].

There are many other potential microbially connected pathways that could contribute to mental health. The role of microbiota in circadian rhythm regulation (and vice versa) is an emerging area of scientific interest [98, 99]. In experimental studies probiotics can upregulate oxytocin [100], a neuropeptide hormone implicated in mood/anxiety and one that can influence both IP and circadian rhythm control $[101,102]$.

\section{Human Microbiota, Mental Health}

Although much more research is required, recent studies have provided evidence of dysbiosis in major depressive disorder (MDD) $[103,104]$. In a recent study the transfer of dysbiotic microbiota derived from patients with MDD to GF mice induced behaviors indicative of depression and also produced disturbances in host metabolites involved in carbohydrate and amino acid metabolism. The behavioral and metabolic 


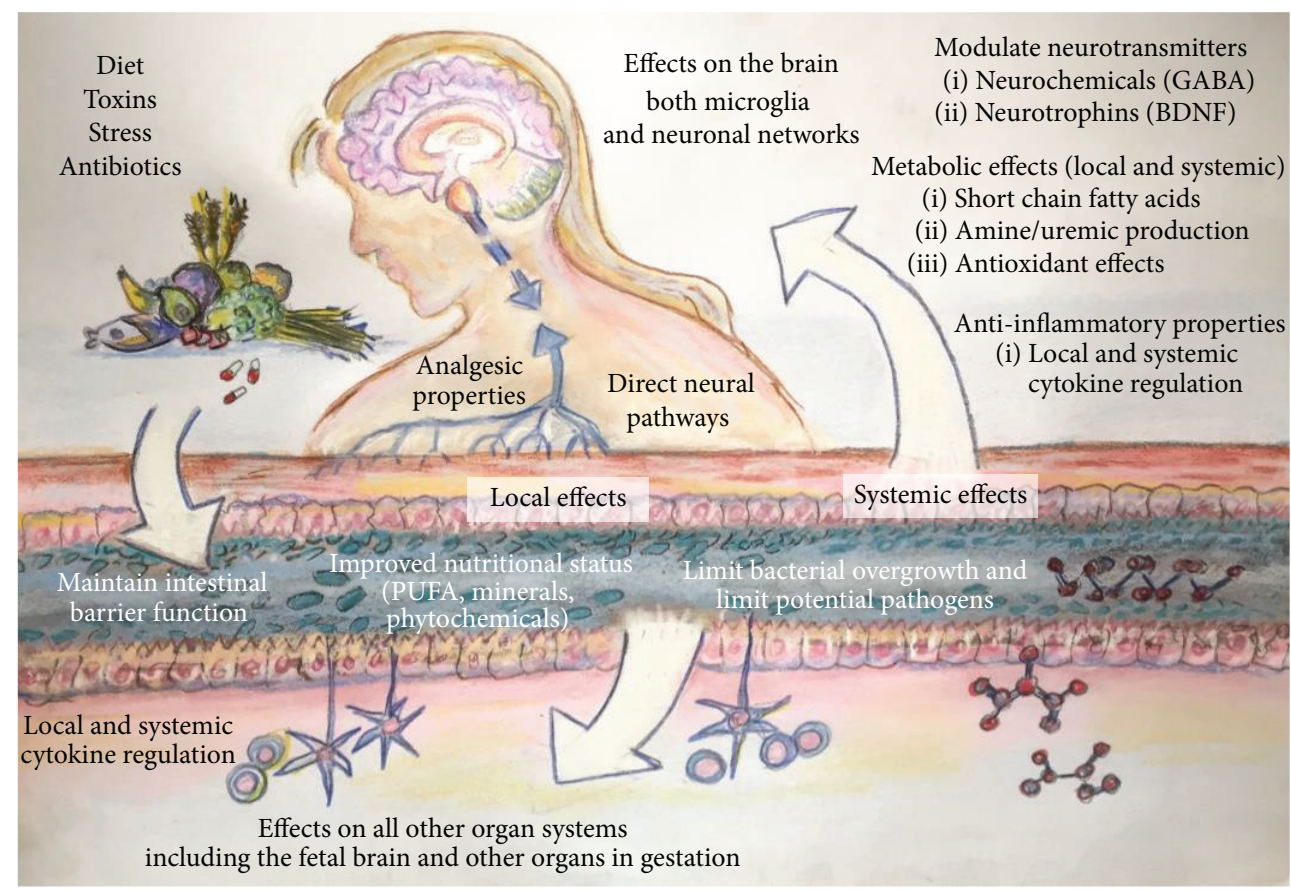

(1) Logan et al. Med Hypotheses, vol. 60, pp. 915-923, Jun 2003

(2) Logan and Katzman, Med Hypotheses, vol. 64, pp. 533-538, 2005

FIGURE 1: Mechanistic pathways originally proposed whereby commensal (or beneficial microbe application) could potentially influence mood and fatigue; many of these have since been documented in experimental models (image: Susan Prescott).

Biodiversity associated lifestyle factors:

A pathway to inflammation and brain disorders?

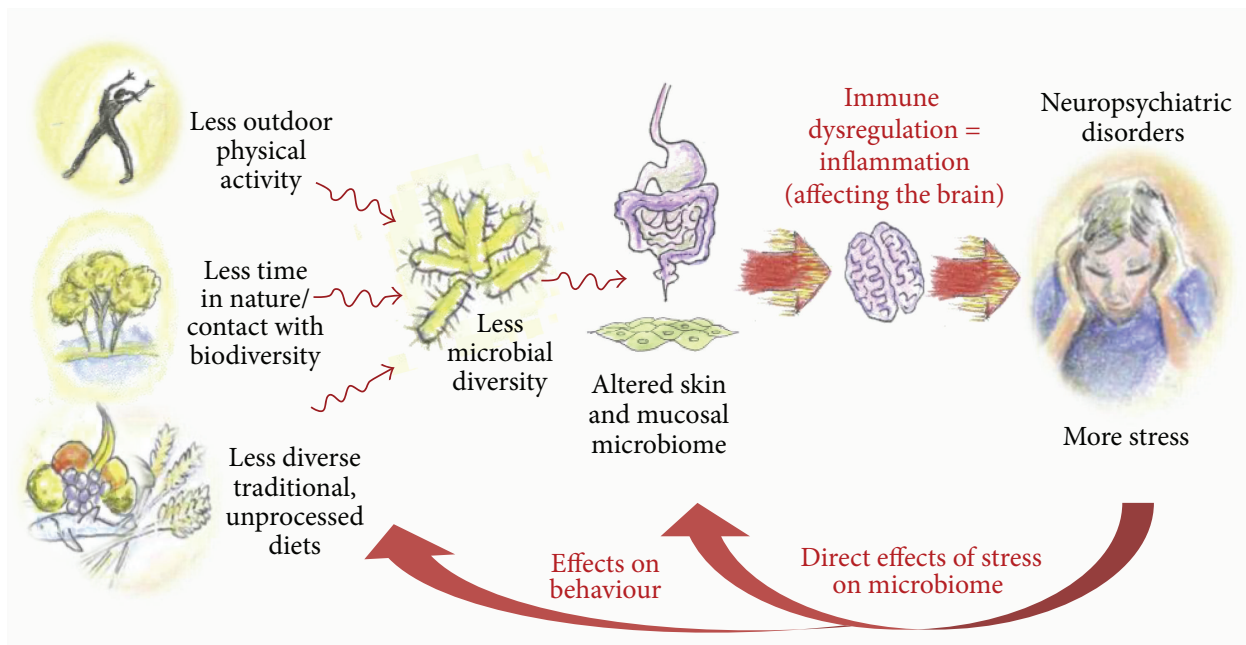

FIGURE 2: In addition to antimicrobial overuse, lifestyle factors may diminish microbial diversity. It is possible that modernity brings loss of contact with biodiversity and places westernized populations in a state of dysbiosis relative to our ancestors. This, in turn, may have immune and mental health consequences (image: Susan Prescott).

changes were distinct from those observed after colonization of GF mice with microbiota derived from healthy human donors [105].

Interestingly, a recent population study found clear associations between antibiotic treatment and the risk of depression and anxiety, a relationship that was largely dose-dependent [106]. In addition, there are also indications that the intestinal barrier may be compromised in depression $[107,108]$, thus providing theoretical support for the idea that systemic access of gut-microbe-derived endotoxin can 
provoke low-grade inflammation and subsequent alterations in mood [109].

At this point it is unclear if the dysbiosis and so-called "leaky gut" are a cause or consequence of depression, or both. The same applies to the many other conditions (in which compromised mood is often a hallmark symptom) where dysbiosis and IP have been implicated; these include, but are not limited to, obesity [110], type 2 diabetes [111], alcohol dependence [112], chronic fatigue syndrome [113], fibromyalgia [114], and cardiovascular disease [115]. Preliminary studies are demonstrating links between gut microbial diversity and brain structure and function in obese and nonobese populations [116].

Several human intervention studies have demonstrated the potential value of nonpathogenic microbes-delivered orally in the form of capsules or in association with fermented beverages-on stress, mood, and anxiety [117-125]. These encouraging studies have generally included healthy adults or nonpsychiatric clinical samples where the endpoints involved mood changes. However, a small but well-designed study has recently shown benefit of a probiotic in MDD. Specifically, patients taking a blend of Lactobacillus acidophilus, Lactobacillus casei, and Bifidobacterium bifidum for 8 weeks had significantly reduced Beck Depression Inventory (BDI) scores versus placebo $(-5.7 \pm 6.4$ versus $-1.5 \pm 4.8, P=0.001)$. In addition, there were decreases in serum insulin, highsensitivity C-reactive protein, and elevations in plasma total glutathione [126].

Additional clinical studies have been identified at clinical trials registry websites. These include ongoing studies involving probiotics in the treatment of bipolar depression [127], obsessive-compulsive disorder [128], attention-deficithyperactivity disorder [129], and MDD where both groups will receive antidepressant monotherapy in addition to a probiotic or placebo [130]. Within the next several years there should be further insight into the clinical utility of various beneficial microbes.

The existing and ongoing clinical trials are supported by aforementioned experimental studies that provide insight into mechanistic pathways; multiple human studies also demonstrate the value of beneficial microbes as a potential means to address the neuroprogression (biological markers) associated with depression and other mental disorders. For example, human studies indicate value of microbes in reducing systemic C-reactive protein [131], shifting toward a less inflammatory cytokine profile [132], reducing systemic oxidative stress [133], and elevating glutathione levels [134]. Studies involving foods and beverages inclusive of beneficial microbes (and/or foods transformed by microbial fermentation or fiber capable of shifting microbial ecology) have also demonstrated beneficial effects on gene expression and various objective markers of stress physiology [135137]. In addition, intriguing studies using functional brain imaging have shown that fermented foods can influence brain activation in ways that might be deemed to provide benefit in emotional regulation [138].

Important to the argument that beneficial microbes can influence mental health are studies demonstrating improved quality of life (QoL) in healthy adults [139] and in those with NCDs that often present with mood-associated symptoms [140-144]. Although it is easy to lament the absence of research involving beneficial microbe administration in patients with specific mental disorders, the research on QoL is not irrelevant. For example, low QoL and the absence of eudemonic well-being are predictive of depression [145]. For now, it can only be concluded that the current body of human research is limited, but encouraging.

\section{Biodiversity, Mental Health, and Immune Dysregulation}

Ecology in the context of public and clinical health is far more than potentially harmful agents such as synthetic chemicals, a point emphasized by microbiologist Rene Dubos in his landmark World Health Organization address on "Human Ecology" (1969):

\section{It is to be hoped that a time will come when human ecology will be able to pay greater attention to the positive and beneficial effects of the environment than to its pathogenic effects.}

In his address Dubos was deeply concerned with what might be missing in the modern, urbanized environments [146].

As one of the earliest researchers focusing on the farreaching consequences of alterations to intestinal microbiota, Dubos was also mindful of the place of microbes in the ecosystems of life (1963):

\section{Animals and man have evolved in intimate asso- ciation with a complex microbial flora. It is to be expected therefore, that many characteristics of their anatomical and physiological development reflect this evolutionary past and are the manifes- tations of tissue responses to the microflora [147].}

Again, with an eye toward what might be missing in modern urban westernized societies, Dubos suggested that a loss of diverse microbial contact in early life (though modernized lifestyle and sanitary habits) could have untold consequences in the long-term functioning of the human immune system [148]. This was almost two decades before the development of the hygiene and microbial deprivation hypotheses. These propositions, along with other similar theoretical variants, suggested that dramatic increases in allergic disease-one of the fist NCDs to present itself in the life course-could be associated with lack of early exposure to pathogenic and evolutionary critical commensal microbes.

Specifically, loss of microbial diversity via increased hygiene, encroachment of highly processed foods, antimicrobial overuse, and diminished contact with natural environments could have far-reaching and long-lasting immune consequences [149]. The complex interactions between highly overlapping allergic, mental health, and gastrointestinal diseases may be mediated by microbial exposures (or lack, thereof) in early life $[37,150]$. The most potent potential for therapeutic targeting of the microbiome may be during this time. 
Landmark reviews, including the 2015 WHO State of Knowledge Report, have underscored the importance of biodiversity (defined as the variety of species, their genetic contribution, and the ecosystems they form) in the promotion of human health [14]. Although humans have only catalogued a small percentage of species on Earth, available evidence indicates that marked reductions in biodiversity are now commonplace [151]. Microbes are critical to the ecosystems that sustain life [152].

The benefits of natural environments-often discussed as "green or blue space"-appear to be particularly strong for mental health [153] and to some degree may be explained via immediate appreciation of scenic aesthetics, opportunity for physical activity, and strengthening of social capital [154]. There are hints that overall biodiversity may be a specific driver of enhanced well-being in various natural environments [155-161]. The mechanisms behind this link are not understood. Since the bark of trees, leaves, and soil are reservoirs of rich microbial diversity, spending time in natural environments, or residing near them, could increase the likelihood that one might encounter unseen biodiversity [162-165]. These microbes found in natural environments can be readily dispersed in the air [166-169].

Some researchers have theorized that microbial biodiversity encountered by contact with natural environments, especially early in life, may be a critical addition to the known health benefits provided by nature and overall biodiversity [170]. This viewpoint is known as the biodiversity hypothesis: "Biodiversity loss leads to reduced interaction between environmental and human microbiotas. This in turn may lead to immune dysfunction and impaired tolerance mechanisms in humans" [171]. Given the immune-mental health connection, and the overlaps between allergic diseases, depression, and functional gastrointestinal disorders, it is no longer difficult to theorize a place for nonharmful environmental microbes in brain and behavior $[172,173]$.

The WHO supports this position and sews together ecology, immunology, and medicine in its recent Biodiversity Report:

Reduced contact of people with the natural environment and biodiversity, and biodiversity loss in the wider environment, leads to reduced diversity in the human microbiota, which itself can lead to immune dysfunction and disease. Considering microbial diversity as an ecosystem service provider may contribute to bridging the chasm between ecology and medicine/immunology, by considering microbial diversity in public health and conservation strategies aimed at maximising services obtained from ecosystems [174].

An additional line of support is from studies that have found early life microbial exposures among those living traditional lifestyles to be associated with a diminished allostatic load (e.g., the inflammatory marker C-reactive protein) when under stress later in life [175]. Again, this suggests that diverse microbial contacts early in life, including those not found in more sanitized/westernized environments, can have long-lasting influences. These signals may interact with lifestyle habits, including time spent outdoors and dietary practices.

Individuals who maintain traditional, nonwesternized lifestyles have higher diversity of gut microbiota [176], and they also differ in their higher frequency of soil microbes found on their hands [177]. It is becoming increasingly clear that dietary factors are not the exclusive road to diversity of human-associated microbes [178-180]. Remarkably, the examination of fecal samples provided by adults living in isolation from western influences shows that approximately $50 \%$ of metagenomic reads are considered "microbial dark matter" (i.e., unidentified microorganisms) [176]. These reads are significantly larger than those observed in westernized adults; the implications are that westernization and urbanization may lead to microbial extinction, or, at the very least, massive underrepresentation (Figure 4).

Given the links between microbial diversity and lowered risk of NCDs, this should be of great concern. Antibiotic overuse is a clear threat to microbial diversity [181]. Contemporary home construction may also be separating humans from airborne microbiota dispersed from natural environments [182]. Sanitary lifestyles may be influencing the diversity of human-associated microbes. Even practices such as the use of dishwashing machines (versus hand washing) [183] and frequent vacuum cleaning [184] may be influencing our contact with microbial diversity.

Emerging research has found differences in cutaneous microbiota among rural versus urban adults [185]. European researchers recently reported that the level of green space and biodiversity of vegetation surrounding one's residence is connected to diversity of select bacteria on the skin and diminished likelihood of allergic responses to common allergens. The amount of greenness surrounding the primary residence appears to be a key driver of commensal skin bacteria $[186,187]$.

The influence of one key microbial family (Gammaproteobacteria) residing on the skin was identified as potentially antiallergenic, and its influence may be far reaching. For example, a particular species within that family, Acinetobacter lwolffii, induced anti-inflammatory gene expression in vitro. More importantly, when injected intradermally in vivo it protected against atopic sensitization and lung inflammation [188]. The systemic effects of diverse commensal cutaneous microbes may be untold.

Since the dermis is not a complete barrier, but rather a filter to microbial access to deeper dermal stroma [189], we can speculate that cutaneous microbes (a product of environmental diversity) may indeed influence aspects of the systemic immune system, including those that influence brain and behavior. Remarkably, the intranasal administration of Acinetobacter lwoffii F78 (a strain common to farm settings, alluded to earlier) prenatally protects against the development of allergic phenotypes in the next generation of mice [190].

Acinetobacter is surely not alone as a health-relevant microbial indicator of reduced contact with biodiversity. Another environmental microbe under increased scrutiny is Mycobacterium vaccae, a generally nonpathogenic microbe 
commonly found in soil and water [191]. Viable Mycobacterium vaccae added to the diet has recently been shown to improve cognition and reduce experimental signs of anxiety in a rodent model [192].

The subcutaneous administration of heat-inactivated $M$. vaccae has been shown to influence serotonergic neurons in the CNS of animals [193]. Moreover, emerging evidence also indicates that heat-inactivated $M$. vaccae can enhance fear extinction (suggesting possible efficacy in conditions such as posttraumatic stress disorder), improve stress coping, and prevent dysbiosis in animal stress models [194, 195]. Potential mechanisms include a suppression of proinflammatory cytokine production. Given that the Earth is home to upward of 1 trillion microbial species [196], it is safe to say that there are many different environmental microbes that may be proven to be therapeutic.

These experimental studies allow for speculation that altered microbial contact might be one mechanism behind the association between neighborhood tree losses and increased risk of NCD over time. For example, the invasive beetle (Agrilus planipennis; emerald ash borer) has been responsible for the mortality of over 100 million trees in northern parts of the USA, and the losses are linked to subsequent increases in cardiovascular disease and lower respiratory tract infections $[197,198]$. There are indications that such losses are associated with decreased time spent outdoors [199]. Thus, altered microbial contact may be a product of vegetative biodiversity loss through direct and indirect pathways.

\section{Is Clinical Ecology the Future of Medical Practice?}

The tendency to disregard ecology in medical research may have far reaching consequences. For example, it facilitates the interpretation of the 'environment' as 'psychosocial environment'. The study of the environment is then implicitly relegated to psychology and social science. No wonder then that mental illness, in the orthodox view, gets a biological interpretation which skimps ecology (van der Steen and Thung; in Faces of Medicine: A Philosophical Study, 1988 [200]).

Advances in the study of the microbiome, including the quest to define what may constitute human microbial "normalcy" in the modern era and the functionality of microbes, have allowed for an entirely new vision of what the future of clinical medicine might look like. Evidence suggests that there is significant variability in the microbiota composition of healthy adults [201]. However, this does not diminish the idea that clinical prevention and therapeutics will be one in which ecology is a key word.

Addressing the microbiota through dietary manipulation, probiotics, prebiotics, bile acid modification, and nextgeneration antibiotics holds significant promise in the clinic (West, [202, 203]). It is even possible that fecal microbiota transfer (FMT) might extend its clinical reach beyond its current focus in Clostridium difficile infection. Preliminary studies have begun to evaluate its usefulness in neurological conditions, including multiple sclerosis and Parkinson's disease [204].

The use of advanced tools, including whole genome sequencing of microbial isolates and communities, is not only determining which specific strains of microbes (beneficial and pathogenic) might be key players in health and disease; they are shedding light on the ways in which select commensal groups can influence these single-strain-related outcomes [205]. This will move clinicians beyond the rudimentary use of probiotics. With the assistance of computational biologists and mathematicians, it is realistic to visualize the marriage of metadata derived from large cohorts to smaller-scale intervention studies to provide the specificity required for clinical translation [206].

In the context of mental health, metagenomic (the genomic analysis of microbial DNA from communities in environmental samples) and proteonomic (examining protein activity to understand disease) analyses will surely provide tremendous intelligence concerning the microbial role in the short and long-term state of the host; prevention and intervention strategies could sit along the continuum between QoL to major mental disorders. Metabolomic (characterization of small-molecule metabolites in biological systems) approaches in the measurement of microbial-generated metabolites, including those related to dietary interventions and pharmacotherapy, will almost certainly help guide clinicians via objective markers that can help determine the most appropriate clinical interventions in the context of personalized medicine [207, 208].

There is now evidence that healthy dietary patterns are associated with reduced risk of depression and that generally such dietary patterns are supportive of microbial diversity [209]. The interaction between diverse microbiota, pharmaceuticals, and dietary supplements will be clinically relevant. Psychotropic medication may influence or be influenced by microbiota [210]. Visualizing ecology for the psychopharmacologist may involve the microbiota as a mediator of propensity to gain weight with use of psychotropic medications. Antidepressant and antipsychoticinduced weight gain is common and may present a barrier to adherence [211]; could subclinical detection of gut microbial biomarkers [212], knowledge of certain microbial profiles [213], and/or microbe-based interventions help attenuate medication-induced weight gain? Moreover, could they actually enhance clinical outcomes?

Researchers are inching ever closer to identifying commensal bacterial genera that may be contributing to NCDs by their relative absence in very early life [214]. In the context of bio-eco-psychological medicine and the $\mathrm{DOHaD}$ construct, the application of these so-called "missing microbes" may hold their greatest promise when applied as a prevention/early intervention approach to the microbiome. Clinical ecology may involve microbial seeding at birth and throughout the lifespan.

However, it is very difficult to imagine addressing largescale NCD-related dysbiosis with effective microbial solutions that are independent of the structures driving dysbiosis in the first place. This may be especially true in the case 


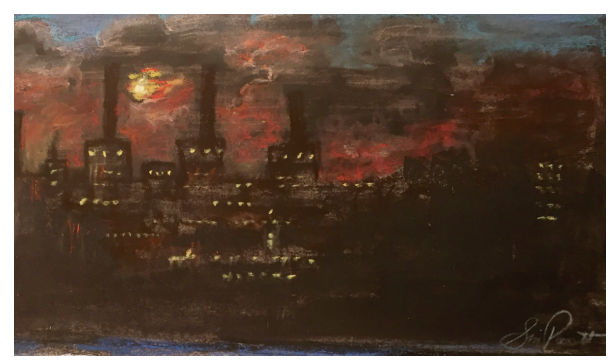

FIGURE 3: Grey space is defined as areas with disproportionately higher industrial and commercial activity, major transportation routes, bars, liquor stores, convenience stores, fast-food outlets, and tobacco vendors. Noise stress, excess light at night, and presence of marketing drivers, billboards, sidewalk signage, and targeted screen media delivery, push a dysbiotic drift. Higher levels of grey space and less equitable access to green space (biodiversity) are an oftenoverlapping burden in disadvantaged populations (image: Susan Prescott).

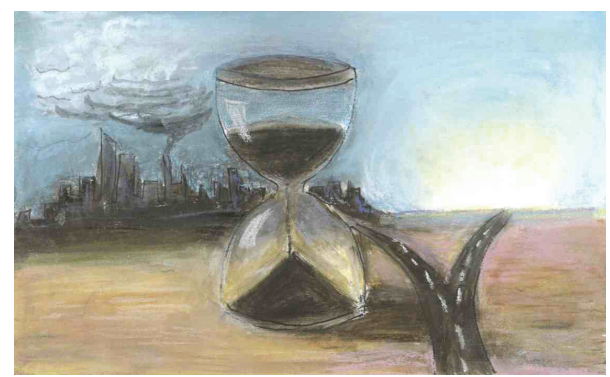

FIGURE 4: The road to dysbiotic drift: factors shown to negatively influence microbiota in either human and/or experimental studies are associated with urbanity and sit on an SES gradient slanted toward disadvantaged populations (see [16]; image: Susan Prescott).

of mental disorders. Lack of equitable access to biodiversity/green space, immersion in grey space, and the marketing forces that drive a "dysbiotic lifestyle" are not without clinical consequence (Figure 3). Therefore, clinical ecology will brush against larger public health and policy initiatives that can prevent dysbiosis at upstream points.

Supplemented to biomedical microbial (probiotic) interventions at the personal level, 21st-century ecology may involve directed exposure of patients to natural environments or manipulation of built and/or indoor environments to enhance exposure to (what may be determined as) keystone species/strains of environmental microbiota. Indoor built environments have "bacterial signatures" based on specifics such as human gender and/or pet occupancy [215]. Further research is required to determine what constitutes a signature of health; with more clarity on that score, ventilation or other more specific airborne exposure techniques may be used to promote health.

The extent to which appropriate public health messaging concerning hygiene meets with blanket fear of all microbes (and the marketing-driven overuse of antimicrobial products) is also an area ripe for clinically relevant research [216]. In the meantime, available evidence certainly supports educating patients on the value of connecting with local "backyard" biodiversity, even in urban settings [217]. Efforts to increase an individual's daily exposure to outdoor biodiversity have been reported to increase personal well-being and overall health [218, 219].

\section{Conclusion}

Advances in microbiome research have influenced every branch of science and medicine. In many ways the evolving science has unified distinct disciplines. Although we still have much to discover, it seems inevitable that personalized medicine will take place in the setting of a new clinical ecology. In this context the external neighborhood (literally, the lifestyle and biodiversity within and around one's area of dwelling) matters to the ecosystems of the skin, intestinal, and other anatomical neighborhoods.

It is becoming clear that evolutionary-rooted relationships between microbiota and host-many mediated at the interface of the immune system-are intertwined with the global burden of NCDs. These NCDs commonly involve chronic, low-grade inflammation and may be referred to as diseases of dysbiotic association [33]. Emerging evidence, both experimental and human, suggests that the microbiome may be a clinically relevant factor in mitigating the neuroprogression associated with mental disorders and subsyndromal variants.

During the last fifty years, the culturally driven pendulum of medical thought concerning many chronic illnesses has swung between dominant psych-to-soma viewpoints and purely biomedical outlooks. Microbial ecology in the clinic (and in the minds of bench scientists generating the discoveries upon which clinicians rely) and the local ecosystems that surround patients may be the ideal meeting place between psychology and biomedicine. It is at this interface that the term "terrain" becomes illuminated. Here it is possible to reconcile the unknowns of why the presence/absence of psychological stress together with the presence/absence of select microbes/microbial communities cannot always explain disease and hence, our bioecopsychological emphasis, wherein ecology is placed as a crucial connector.

Whether a patient arrives for a preventative or therapeutic visit, it is likely that evidence-based clinicians will increasingly see this holistic perspective. Academics are already calling for microbiology and ecology to have an elevated place in mandatory undergraduate premedicine requisites [220] and the integration of biodiversity, ecological health, and ecosystem services within the course curriculum of doctorate of medicine programs [221, 222]. How do pharmaceutical interventions, dietary advice, physical activity recommendations, sleep hygiene suggestions, and a host of other considerations that brush up against lifestyle medicine impact ecosystems? Conversely, how does the microbiome influence so many aspects of prescriptive clinical medicine?

Modern clinicians will be increasingly reliant upon cutting edge algorithms and metabolomics-driven blood and urine tests for diagnostics/treatment; however, they will need to understand the psychological and ecological factors that 
could impact successful outcomes. Approaching patients from the holobiont perspective, even now, forces hard questions concerning lifestyle and behaviors that might contribute to dysbiotic drift. The individual is not detached from the ecological theatre in which they reside. Therefore, bio-ecopsychological approach will assuredly lead to increased efficacy of the biotechnical approaches that are on the horizon.

Existing research thus indicates that although the future of medicine will be personalized, it is likely to occur with an emphasis on the contextual framework involving broad ecosystems. While the World Health Organization rightly maintains that there is "No Health Without Mental Health," in the larger scheme there is in reality "No Health Without Ecological Health." Put simply, there can be no personal or planetary health without diverse ecosystems operating both on and within the body and also in the larger sense as fueled by biodiversity.

From this perspective there will be an increased need for clinicians to play a larger role in the way they might see patient care. A recent commentary in the Canadian Medical Association Journal states the following:

Some physicians shy away from engaging with wider social issues, focusing instead on the individual patient. However, when it comes to action on climate change, such a position becomes untenable given that many of the measures that could mitigate harmful environmental effects would also be of direct benefit to individual health [223].

The links between climate change and biodiversity loss are obvious. We would extend this prescriptive commentary to include grey space, lifestyle variables, inequalities in access to biodiversity, and the policies that either drive ecological inequalities or, at the very least, leave them in place. These, too, in the context of "missing microbes," could possibly mitigate large-scale environmental influences on individual health. As we have emphasized, there is much more to learn; however, the line between the ecosystems at the global level and the ecosystem sitting on a single intestinal villus is a short one.

Dubos maintained that medicine with ecology in mind must maintain awareness of the ecosystems of today. He was deeply concerned that medical philosophy was not attendant enough to the early origins of health and disease and short-sighted policies that ripple into multigenerational ill-health [224]. His concerns are no less relevant today as we seek solutions to antibiotic overuse, biodiversity loss, ultraprocessed foods, and a pandemic of chronic, NCDs.

\section{Disclosure}

Susan L. Prescott and Alan C. Logan are affiliated with International Inflammation (in-FLAME) Network, Worldwide Universities Network (WUN).

\section{Competing Interests}

Susan L. Prescott reports the following: Scientific Advisory Board and speakers fees from Danone Nutricia,
Schiphol, Netherlands, and Nestlé Nutrition Institute, Lausanne, Switzerland; being compensated consultant to Bayer Pharmaceuticals, Whippany, NJ, USA; Alan C. Logan has received consultancy fees from Genuine Health, Toronto, Canada. Rachel A. Millstein and Martin A. Katzman declare no conflict of interests.

\section{References}

[1] S. F. Gilbert, J. Sapp, and A. I. Tauber, "A symbiotic view of life: we have never been individuals," Quarterly Review of Biology, vol. 87, no. 4, pp. 325-341, 2012.

[2] S. R. Bordenstein and K. R. Theis, "Host biology in light of the microbiome: ten principles of holobionts and hologenomes," PLoS Biology, vol. 13, no. 8, Article ID e1002226, 2015.

[3] A. E. Douglas and J. H. Werren, "Holes in the hologenome: why host-microbe symbioses are not holobionts," mBio, vol. 7, Article ID e02099-15, 2016.

[4] R. Sender, S. Fuchs, and R. Milo, "Are we really vastly outnumbered? Revisiting the ratio of bacterial to host cells in humans," Cell, vol. 164, no. 3, pp. 337-340, 2016.

[5] K. Lu, R. Mahbub, and J. G. Fox, "Xenobiotics: interaction with the intestinal microflora," ILAR Journal, vol. 56, no. 2, pp. 218 227, 2015.

[6] M. J. Blaser, "The microbiome revolution," Journal of Clinical Investigation, vol. 124, no. 10, pp. 4162-4165, 2014.

[7] D. A. Relman, "The human microbiome and the future practice of medicine," Journal of the American Medical Association, vol. 314, no. 11, pp. 1127-1128, 2015.

[8] A. C. Logan, F. N. Jacka, J. M. Craig, and S. L. Prescott, "The microbiome and mental health: looking back, moving forward with lessons from allergic diseases," Clinical Psychopharmacology and Neuroscience, vol. 14, no. 2, pp. 131-147, 2016.

[9] G. L. Engel, "The need for a new medical model: a challenge for biomedicine," Science, vol. 196, no. 4286, pp. 129-136, 1977.

[10] K. Garber, "Drugging the gut microbiome," Nature Biotechnology, vol. 33, no. 3, pp. 228-231, 2016.

[11] S. Reardon, "Gut-brain link grabs neuroscientists," Nature, vol. 515, no. 7526, pp. 175-176, 2014.

[12] B. J. Cardinale, J. E. Duffy, A. Gonzalez et al., "Biodiversity loss and its impact on humanity," Nature, vol. 486, no. 7401, pp. 5967, 2012.

[13] A. S. Bernstein, "Biological diversity and public health," Annual Review of Public Health, vol. 35, pp. 153-167, 2014.

[14] World Health Organization, Connecting Global Priorities: Biodiversity and Human Health: A State of Knowledge Review, World Health Organization and Secretariat of the Convention on Biological Diversity, 2015.

[15] World Health Organization, Mental Health: Strengthening Our Response. WHO Fact Sheet $N^{\circ} 220$, World Health Organization, Geneva, Switzerland, 2014.

[16] A. C. Logan, "Dysbiotic drift: mental health, environmental grey space, and microbiota," Journal of Physiological Anthropology, vol. 34, article 23, 2015.

[17] R. Hunter, The Encyclopoedic Dictionary, Volume 2, Part 1, Cassell, Petter \& Galpin, London, UK, 1882.

[18] B. S. Ramakrishna, "Role of the gut microbiota in human nutrition and metabolism," Journal of Gastroenterology and Hepatology, vol. 28, no. 4, pp. 9-17, 2013. 
[19] S. M. Jandhyala, R. Talukdar, C. Subramanyam, H. Vuyyuru, M. Sasikala, and D. N. Reddy, "Role of the normal gut microbiota," World Journal of Gastroenterology, vol. 21, no. 29, pp. 8836-8847, 2015.

[20] A. C. Logan, F. N. Jacka, and S. L. Prescott, "Immune-microbiota interactions: dysbiosis as a global health issue," Current Allergy and Asthma Reports, vol. 16, article 13, 2016.

[21] C. Petersen and J. L. Round, "Defining dysbiosis and its influence on host immunity and disease," Cellular Microbiology, vol. 16, no. 7, pp. 1024-1033, 2014.

[22] R. Dubos, Man Adapting, Yale University Press, New Haven, Conn, USA, 1965.

[23] R. Dubos, D. Savage, and R. Schaedler, "Biological Freudianism. Lasting effects of early environmental influences," Pediatrics, vol. 38 , no. 5, pp. 789-800, 1966.

[24] L. R. Hegstrand and R. J. Hine, "Variations of brain histamine levels in germ-free and nephrectomized rats," Neurochemical Research, vol. 11, no. 2, pp. 185-191, 1986.

[25] M. Al-Asmakh and F. Zadjali, "Use of germ-free animal models in microbiota-related research," Journal of Microbiology and Biotechnology, vol. 25, no. 10, pp. 1583-1588, 2015.

[26] J. M. Rodríguez, K. Murphy, C. Stanton et al., "The composition of the gut microbiota throughout life, with an emphasis on early life," Microbial Ecology in Health \& Disease, vol. 26, Article ID 26050, 2015.

[27] K. Aagaard, J. Ma, K. M. Antony, R. Ganu, J. Petrosino, and J. Versalovic, "The placenta harbors a unique microbiome," Science Translational Medicine, vol. 6, no. 237, Article ID 237ra65, 2014.

[28] E. B. Hollister, K. Riehle, R. A. Luna et al., "Structure and function of the healthy pre-adolescent pediatric gut microbiome," Microbiome, vol. 3, article 36, 2015.

[29] E. Avershina and K. Rudi, "Confusion about the species richness of human gut microbiota," Beneficial Microbes, vol. 6, no. 5, pp. 657-659, 2015.

[30] N.-R. Shin, T. W. Whon, and J.-W. Bae, "Proteobacteria: microbial signature of dysbiosis in gut microbiota," Trends in Biotechnology, vol. 33, no. 9, pp. 496-503, 2015.

[31] L. G. Albenberg and G. D. Wu, "Diet and the intestinal microbiome: associations, functions, and implications for health and disease," Gastroenterology, vol. 146, no. 6, pp. 1564-1572, 2014.

[32] M.-C. Arrieta, L. T. Stiemsma, P. A. Dimitriu et al., "Early infancy microbial and metabolic alterations affect risk of childhood asthma," Science Translational Medicine, vol. 7, no. 307, Article ID 307ra152, 2015.

[33] C. E. West, H. Renz, M. C. Jenmalm et al., "The gut microbiota and inflammatory noncommunicable diseases: associations and potentials for gut microbiota therapies," Journal of Allergy and Clinical Immunology, vol. 135, no. 1, pp. 3-14, 2015.

[34] J. R. Marchesi, D. H. Adams, F. Fava et al., "The gut microbiota and host health: a new clinical frontier," Gut, vol. 65, no. 2, pp. 330-339, 2016.

[35] E. Uphoff, B. Cabieses, M. Pinart, M. Valdés, J. Maria Antó, and J. Wright, "A systematic review of socioeconomic position in relation to asthma and allergic diseases," European Respiratory Journal, vol. 46, no. 2, pp. 364-374, 2015.

[36] M. Marmot, "The health gap: the challenge of an unequal world," The Lancet, vol. 386, no. 10011, pp. 2442-2444, 2015.

[37] S. L. Prescott, "Disease prevention in the age of convergencethe need for a wider, long ranging and collaborative vision," Allergology International, vol. 63, no. 1, pp. 11-20, 2014.
[38] T. Oni and N. Unwin, "Why the communicable/non-communicable disease dichotomy is problematic for public health control strategies: implications of multimorbidity for health systems in an era of health transition," International Health, vol. 7, no. 6, pp. 390-399, 2015.

[39] I. Gutiérrez-Díaz, T. Fernández-Navarro, B. Sánchez, A. Margolles, and S. González, "Mediterranean diet and faecal microbiota: a transversal study," Food \& Function, vol. 7, no. 5, pp. 2347-2356, 2016.

[40] B. Vitali, G. Minervini, C. G. Rizzello et al., "Novel probiotic candidates for humans isolated from raw fruits and vegetables," Food Microbiology, vol. 31, no. 1, pp. 116-125, 2012.

[41] O. S. von Ehrenstein, H. Aralis, M. E. S. Flores, and B. Ritz, "Fast food consumption in pregnancy and subsequent asthma symptoms in young children," Pediatric Allergy and Immunology, vol. 26, no. 6, pp. 571-577, 2015.

[42] H. S. Cui, I. S. Ahn, Y. S. Byun et al., "Dietary pattern and nutrient intake of Korean children with atopic dermatitis," Annals of Dermatology, vol. 26, no. 5, pp. 570-575, 2014.

[43] A. Sánchez-Villegas, P. Henríquez-Sánchez, M. Ruiz-Canela et al., "A longitudinal analysis of diet quality scores and the risk of incident depression in the SUN Project," BMC Medicine, vol. 13, article 197, 2015.

[44] L. A. David, C. F. Maurice, R. N. Carmody et al., "Diet rapidly and reproducibly alters the human gut microbiome," Nature, vol. 505, no. 7484, pp. 559-563, 2014.

[45] Z. Xu and R. Knight, "Dietary effects on human gut microbiome diversity," The British Journal of Nutrition, vol. 113, pp. S1-S5, 2015.

[46] J. Tap, J.-P. Furet, M. Bensaada et al., "Gut microbiota richness promotes its stability upon increased dietary fibre intake in healthy adults," Environmental Microbiology, vol. 17, no. 12, pp. 4954-4964, 2015.

[47] A. Cotillard, S. P. Kennedy, L. C. Kong et al., "Dietary intervention impact on gut microbial gene richness," Nature, vol. 500, pp. 585-588, 2013.

[48] E. Le Chatelier, T. Nielsen, J. Qin et al., "Richness of human gut microbiome correlates with metabolic markers," Nature, vol. 500, pp. 541-546, 2013.

[49] T. W. McDade, "Early environments and the ecology of inflammation," Proceedings of the National Academy of Sciences of the United States of America, vol. 109, supplement 2, pp. 1728117288, 2012.

[50] G. E. Miller, P. A. Engen, P. M. Gillevet et al., "Lower neighborhood socioeconomic status associated with reduced diversity of the colonic microbiota in healthy adults," PLOS ONE, vol. 11, no. 2, Article ID e0148952, 2016.

[51] C. W. Chong, A. F. Ahmad, Y. A. L. Lim et al., "Effect of ethnicity and socioeconomic variation to the gut microbiota composition among pre-adolescent in Malaysia," Scientific Reports, vol. 5, Article ID 13338, 2015.

[52] R. M. Maizels, H. J. Mcsorley, and D. J. Smyth, "Helminths in the hygiene hypothesis: sooner or later?" Clinical and Experimental Immunology, vol. 177, no. 1, pp. 38-46, 2014.

[53] R. Moodie, D. Stuckler, C. Monteiro et al., "Profits and pandemics: prevention of harmful effects of tobacco, alcohol, and ultra-processed food and drink industries," The Lancet, vol. 381, no. 9867, pp. 670-679, 2013.

[54] E. M. Selhub, A. C. Logan, and A. C. Bested, "Fermented foods, microbiota, and mental health: ancient practice meets nutritional psychiatry," Journal of Physiological Anthropology, vol. 33, no. 1, article 2, 2014. 
[55] E. D. Sonnenburg, S. A. Smits, M. Tikhonov, S. K. Higginbottom, N. S. Wingreen, and J. L. Sonnenburg, "Diet-induced extinctions in the gut microbiota compound over generations," Nature, vol. 529, no. 7585, pp. 212-215, 2016.

[56] S. R. Knowles, E. A. Nelson, and E. A. Palombo, "Investigating the role of perceived stress on bacterial flora activity and salivary cortisol secretion: a possible mechanism underlying susceptibility to illness," Biological Psychology, vol. 77, no. 2, pp. 132-137, 2008.

[57] J. Sundin, I. Rangel, S. Fuentes et al., "Altered faecal and mucosal microbial composition in post-infectious irritable bowel syndrome patients correlates with mucosal lymphocyte phenotypes and psychological distress," Alimentary Pharmacology and Therapeutics, vol. 41, no. 4, pp. 342-351, 2015.

[58] M. A. C. Zijlmans, K. Korpela, J. M. Riksen-Walraven, W. M. de Vos, and C. de Weerth, "Maternal prenatal stress is associated with the infant intestinal microbiota," Psychoneuroendocrinology, vol. 53, pp. 233-245, 2015.

[59] T. S. Cheng, H. Chen, T. Lee et al., "An independent association of prenatal depression with wheezing and anxiety with rhinitis in infancy," Pediatric Allergy and Immunology, vol. 26, no. 8, pp. 765-771, 2016.

[60] P. C. Konturek, T. Brzozowski, and S. J. Konturek, "Stress and the gut: pathophysiology, clinical consequences, diagnostic approach and treatment options," Journal of Physiology and Pharmacology, vol. 62, no. 6, pp. 591-599, 2011.

[61] A. C. Logan and F. N. Jacka, "Nutritional psychiatry research: an emerging discipline and its intersection with global urbanization, environmental challenges and the evolutionary mismatch," Journal of Physiological Anthropology, vol. 33, article 22, 2014.

[62] N. Zeeni, M. Bassil, G. Fromentin et al., "Environmental enrichment and cafeteria diet attenuate the response to chronic variable stress in rats," Physiology \& Behavior, vol. 139, pp. 41-49, 2015.

[63] L. E. Finch and A. J. Tomiyama, "Comfort eating, psychological stress, and depressive symptoms in young adult women," Appetite, vol. 95, pp. 239-244, 2015.

[64] A. Agus, J. Denizot, J. Thévenot et al., "Western diet induces a shift in microbiota composition enhancing susceptibility to Adherent-Invasive E. coli infection and intestinal inflammation," Scientific Reports, vol. 6, Article ID 19032, 2016.

[65] T. L. Gur and M. T. Bailey, "Effects of stress on commensal microbes and immune system activity," Advances in Experimental Medicine and Biology, vol. 874, pp. 289-300, 2016.

[66] J. D. Galley, Z. Yu, P. Kumar, S. E. Dowd, M. Lyte, and M. T. Bailey, "The structures of the colonic mucosa-associated and luminal microbial communities are distinct and differentially affected by a prolonged murine stressor," Gut Microbes, vol. 5, no. 6, pp. 748-760, 2015.

[67] B. T. Green and D. R. Brown, "Interactions between bacteria and the gut mucosa: do enteric neurotransmitters acting on the mucosal epithelium influence intestinal colonization or infection?" Advances in Experimental Medicine and Biology, vol. 874, pp. 121-141, 2016.

[68] C. Chehoud, S. Rafail, A. S. Tyldsley, J. T. Seykora, J. D. Lambris, and E. A. Grice, "Complement modulates the cutaneous microbiome and inflammatory milieu," Proceedings of the National Academy of Sciences of the United States of America, vol. 110, no. 37, pp. 15061-15066, 2013.

[69] J. D. Lewis, E. Z. Chen, R. N. Baldassano et al., "Inflammation, antibiotics, and diet as environmental stressors of the gut microbiome in pediatric Crohn's dsease," Cell Host and Microbe, vol. 18, no. 4, pp. 489-500, 2015.

[70] A. Bharwani, M. F. Mian, J. A. Foster, M. G. Surette, J. Bienenstock, and P. Forsythe, "Structural \& functional consequences of chronic psychosocial stress on the microbiome \& host," Psychoneuroendocrinology, vol. 63, pp. 217-227, 2016.

[71] F. López-Muñoz, A. A. Baumeister, M. F. Hawkins, and C. Álamo, "The role of serendipity in the discovery of the clinical effects of psychotropic drugs: beyond of the myth," Actas Espanolas de Psiquiatria, vol. 40, no. 1, pp. 34-42, 2012.

[72] A. J. Prange Jr., "The pharmacology and biochemistry of depression," Diseases of the Nervous System, vol. 25, pp. 217-221, 1964.

[73] R. M. Lattey, "Dr. Sigmund freud, pseudoscientist," Canadian Family Physician, vol. 15, pp. 59-63, 1969.

[74] M. Knobel, “The environmental 'antidrug' effect," Psychiatry, vol. 23, pp. 403-407, 1960.

[75] B. Marshall and M. Azad, "Q\&A: Barry Marshall. A bold experiment," Nature, vol. 514, no. 7522, pp. S6-S7, 2014.

[76] M. Radić, "Role of Helicobacter pylori infection in autoimmune systemic rheumatic diseases," World Journal of Gastroenterology, vol. 20, no. 36, pp. 12839-12846, 2014.

[77] J. Su, X.-Y. Zhou, and G.-X. Zhang, "Association between Helicobacter pylori infection and migraine: a meta-analysis," World Journal of Gastroenterology, vol. 20, no. 40, pp. 1496514972, 2014.

[78] Y. Xu, Q. Wang, Y. Liu, R. Cui, and Y. Zhao, "Is Helicobacter pylori infection a critical risk factor for vascular dementia?" International Journal of Neuroscience, vol. 126, no. 10, pp. 899903, 2016.

[79] M. Kucukazman, O. Yeniova, K. Dal, and B. Yavuz, "Helicobacter pylori and cardiovascular disease," European Review for Medical and Pharmacological Sciences, vol. 19, pp. 3731-3741, 2015.

[80] T. Khamechian, A. H. Movahedian, G. E. Eskandari, M. H. Arani, and A. Mohammadi, "Evaluation of the correlation between childhood asthma and Helicobacter pylori in Kashan," Jundishapur Journal of Microbiology, vol. 8, no. 6, Article ID e17842, 2015.

[81] E. Lionetti, S. Leonardi, A. Lanzafame et al., "Helicobacter pylori infection and atopic diseases: is there a relationship? A systematic review and meta-analysis," World Journal of Gastroenterology, vol. 20, no. 46, pp. 17635-17647, 2014.

[82] S. Levenstein, S. Rosenstock, R. K. Jacobsen, and T. Jorgensen, "Psychological stress increases risk for peptic ulcer, regardless of helicobacter pylori infection or use of nonsteroidal antiinflammatory drugs," Clinical Gastroenterology and Hepatology, vol. 13, no. 3, pp. 498-506.e1, 2015.

[83] J. C. Atherton and M. J. Blaser, "Coadaptation of Helicobacter pylori and humans: ancient history, modern implications," The Journal of Clinical Investigation, vol. 119, no. 9, pp. 2475-2487, 2009.

[84] G. A. W. Rook, "The hygiene hypothesis and the increasing prevalence of chronic inflammatory disorders," Transactions of the Royal Society of Tropical Medicine and Hygiene, vol. 101, no. 11, pp. 1072-1074, 2007.

[85] N. Sudo, Y. Chida, Y. Aiba et al., "Postnatal microbial colonization programs the hypothalamic-pituitary-adrenal system for stress response in mice," Journal of Physiology, vol. 558, no. 1, pp. 263-275, 2004. 
[86] J. R. Kelly, G. Clarke, J. F. Cryan, and T. G. Dinan, "Brain-gutmicrobiota axis: challenges for translation in psychiatry," Annals of Epidemiology, vol. 26, no. 5, pp. 366-372, 2016.

[87] E. Sherwin, K. Rea, T. G. Dinan, and J. F. Cryan, "A gut (microbiome) feeling about the brain," Current Opinion in Gastroenterology, vol. 32, no. 2, pp. 96-102, 2016.

[88] A. C. Logan, A. V. Rao, and D. Irani, "Chronic fatigue syndrome: lactic acid bacteria may be of therapeutic value," Medical Hypotheses, vol. 60, no. 6, pp. 915-923, 2003.

[89] A. C. Logan and M. Katzman, "Major depressive disorder: probiotics may be an adjuvant therapy," Medical Hypotheses, vol. 64, no. 3, pp. 533-538, 2005.

[90] P. Bercik, A. J. Park, D. Sinclair et al., "The anxiolytic effect of Bifidobacterium longum NCC3001 involves vagal pathways for gut-brain communication," Neurogastroenterology and Motility, vol. 23, no. 12, pp. 1132-1139, 2011.

[91] J. A. Bravo, P. Forsythe, M. V. Chew et al., "Ingestion of Lactobacillus strain regulates emotional behavior and central GABA receptor expression in a mouse via the vagus nerve," Proceedings of the National Academy of Sciences of the United States of America, vol. 108, no. 38, pp. 16050-16055, 2011.

[92] P. Bercik, E. F. Verdu, J. A. Foster et al., “Chronic gastrointestinal inflammation induces anxiety-like behavior and alters central nervous system biochemistry in mice," Gastroenterology, vol. 139, no. 6, pp. 2102.e1-2112.e1, 2010.

[93] T. G. Dinan and J. F. Cryan, "Mood by microbe: towards clinical translation," Genome Medicine, vol. 8, no. 1, article 36, 2016.

[94] P. Bercik, E. Denou, J. Collins et al., "The intestinal microbiota affect central levels of brain-derived neurotropic factor and behavior in mice," Gastroenterology, vol. 141, no. 2, pp. 599609.e3, 2011.

[95] A. J. Bruce-Keller, J. M. Salbaum, M. Luo et al., “Obese-type gut microbiota induce neurobehavioral changes in the absence of obesity," Biological Psychiatry, vol. 77, no. 7, Article ID 12273, pp. 607-615, 2015.

[96] K. Kaliannan, B. Wang, X.-Y. Li, K.-J. Kim, and J. X. Kang, "A host-microbiome interaction mediates the opposing effects of omega- 6 and omega-3 fatty acids on metabolic endotoxemia," Scientific Reports, vol. 5, Article ID 11276, 2015.

[97] A. Ait-Belgnaoui, A. Colom, V. Braniste et al., "Probiotic gut effect prevents the chronic psychological stress-induced brain activity abnormality in mice," Neurogastroenterology and Motility, vol. 26, no. 4, pp. 510-520, 2014.

[98] R. M. Voigt, K. C. Summa, C. B. Forsyth et al., "The circadian clock mutation promotes intestinal dysbiosis," Alcoholism: Clinical and Experimental Research, vol. 40, no. 2, pp. 335-347, 2016.

[99] E. V. Marcinkevicius and M. M. Shirasu-Hiza, "Message in a biota: gut microbes signal to the circadian clock," Cell Host and Microbe, vol. 17, no. 5, pp. 541-543, 2015.

[100] S. E. Erdman and T. Poutahidis, "Probiotic 'glow of health': it's more than skin deep," Beneficial Microbes, vol. 5, no. 2, pp. 109119, 2014.

[101] M. G. Welch, K. G. Margolis, Z. Li, and M. D. Gershon, "Oxytocin regulates gastrointestinal motility, inflammation, macromolecular permeability, and mucosal maintenance in mice," American Journal of Physiology-Gastrointestinal and Liver Physiology, vol. 307, no. 8, pp. G848-G862, 2014.

[102] R. L. Gannon, "Non-peptide oxytocin receptor ligands and hamster circadian wheel running rhythms," Brain Research, vol. 1585, pp. 184-190, 2014.
[103] H. Jiang, Z. Ling, Y. Zhang et al., "Altered fecal microbiota composition in patients with major depressive disorder," Brain, Behavior, and Immunity, vol. 48, pp. 186-194, 2015.

[104] A. Naseribafrouei, K. Hestad, E. Avershina et al., "Correlation between the human fecal microbiota and depression," Neurogastroenterology and Motility, vol. 26, no. 8, pp. 1155-1162, 2014.

[105] P. Zheng, B. Zeng, C. Zhou et al., "Gut microbiome remodeling induces depressive-like behaviors through a pathway mediated by the host's metabolism," Molecular Psychiatry, vol. 21, no. 6, pp. 786-796, 2016.

[106] I. Lurie, Y.-X. Yang, K. Haynes, R. Mamtani, and B. Boursi, "Antibiotic exposure and the risk for depression, anxiety, or psychosis: a nested case-control study," Journal of Clinical Psychiatry, vol. 76, no. 11, pp. 1522-1528, 2015.

[107] M. Maes, M. Kubera, J.-C. Leunis, and M. Berk, "Increased IgA and IgM responses against gut commensals in chronic depression: further evidence for increased bacterial translocation or leaky gut," Journal of Affective Disorders, vol. 141, no. 1, pp. 5562, 2012.

[108] M. Maes, I. Mihaylova, M. Kubera, and J.-C. Leunis, "An IgM-mediated immune response directed against nitro-bovine serum albumin (nitro-BSA) in chronic fatigue syndrome (CFS) and major depression: evidence that nitrosative stress is another factor underpinning the comorbidity between major depression and CFS," Neuroendocrinology Letters, vol. 29, no. 3, pp. 313-319, 2008.

[109] J. R. Kelly, P. J. Kennedy, J. F. Cryan, T. G. Dinan, G. Clarke, and N. P. Hyland, "Breaking down the barriers: the gut microbiome, intestinal permeability and stress-related psychiatric disorders," Frontiers in Cellular Neuroscience, vol. 9, article 392, 2015.

[110] S. Xiao, N. Fei, X. Pang et al., "A gut microbiota-targeted dietary intervention for amelioration of chronic inflammation underlying metabolic syndrome," FEMS Microbiology Ecology, vol. 87, no. 2, pp. 357-367, 2014.

[111] F. Horton, J. Wright, L. Smith, P. J. Hinton, and M. D. Robertson, "Increased intestinal permeability to oral chromium (51Cr) EDTA in human Type 2 diabetes," Diabetic Medicine, vol. 31, no. 5, pp. 559-563, 2014.

[112] P. de Timary, S. Leclercq, P. Stärkel, and N. Delzenne, "A dysbiotic subpopulation of alcohol-dependent subjects," Gut Microbes, vol. 6, no. 6, pp. 388-391, 2015.

[113] S. K. Shukla, D. Cook, J. Meyer et al., "Changes in gut and plasma Microbiome following exercise challenge in Myalgic encephalomyelitis/chronic fatigue syndrome (ME/CFS)," PLoS ONE, vol. 10, no. 12, article e0145453, 2015.

[114] A. Goebel, S. Buhner, R. Schedel, H. Lochs, and G. Sprotte, "Altered intestinal permeability in patients with primary fibromyalgia and in patients with complex regional pain syndrome," Rheumatology, vol. 47, no. 8, pp. 1223-1227, 2008.

[115] T. Yang, M. M. Santisteban, V. Rodriguez et al., "Gut dysbiosis is linked to hypertension," Hypertension, vol. 65, no. 6, pp. 13311340, 2015.

[116] J.-M. Fernandez-Real, M. Serino, G. Blasco et al., "Gut microbiota interacts with brain microstructure and function," The Journal of Clinical Endocrinology \& Metabolism, vol. 100, no. 12, pp. 4505-4513, 2015.

[117] D. Benton, C. Williams, and A. Brown, "Impact of consuming a milk drink containing a probiotic on mood and cognition," European Journal of Clinical Nutrition, vol. 61, no. 3, pp. 355361, 2007.

[118] A. V. Rao, A. C. Bested, T. M. Beaulne et al., "A randomized, double-blind, placebo-controlled pilot study of a probiotic 
in emotional symptoms of chronic fatigue syndrome," Gut Pathogens, vol. 1, article 6, 2009.

[119] M. Messaoudi, R. Lalonde, N. Violle et al., "Assessment of psychotropic-like properties of a probiotic formulation (Lactobacillus helveticus R0052 and Bifidobacterium longum R0175) in rats and human subjects," British Journal of Nutrition, vol. 105, no. 5, pp. 755-764, 2011.

[120] T. Sashihara, M. Nagata, T. Mori et al., "Effects of lactobacillus gasseri OLL2809 and $\alpha$-lactalbumin on university-student athletes: a randomized, double-blind, placebo-controlled clinical trial," Applied Physiology, Nutrition and Metabolism, vol. 38, no. 12, pp. 1228-1235, 2013.

[121] A. Pärtty, M. Kalliomäki, P. Wacklin, S. Salminen, and E. Isolauri, "A possible link between early probiotic intervention and the risk of neuropsychiatric disorders later in childhood: a randomized trial," Pediatric Research, vol. 77, no. 6, pp. 823-828, 2015.

[122] L. Steenbergen, R. Sellaro, S. van Hemert, J. A. Bosch, and L. S. Colzato, "A randomized controlled trial to test the effect of multispecies probiotics on cognitive reactivity to sad mood," Brain, Behavior, and Immunity, vol. 48, pp. 258-264, 2015.

[123] M. Messaoudi, N. Violle, J.-F. Bisson, D. Desor, H. Javelot, and C. Rougeot, "Beneficial psychological effects of a probiotic formulation (Lactobacillus helveticus R0052 and Bifidobacterium longum R0175) in healthy human volunteers," Gut Microbes, vol. 2, no. 4, pp. 256-261, 2011.

[124] M. Takada, K. Nishida, A. Kataoka-Kato et al., "Probiotic Lactobacillus casei strain Shirota relieves stress-associated symptoms by modulating the gut-brain interaction in human and animal models," Neurogastroenterology \& Motility, vol. 28, no. 7, pp. 1027-1036, 2016.

[125] T. Culpepper, M. C. Christman, C. Nieves et al., "Bifidobacterium bifidum R0071 decreases stress-associated diarrhoearelated symptoms and self-reported stress: a secondary analysis of a randomised trial," Beneficial Microbes, vol. 7, no. 3, pp. 327336, 2016.

[126] G. Akkasheh, Z. Kashani-Poor, M. Tajabadi-Ebrahimi et al., "Clinical and metabolic response to probiotic administration in patients with major depressive disorder: a randomized, doubleblind, placebo-controlled trial," Nutrition, vol. 32, no. 3, pp. 315320, 2016.

[127] https://clinicaltrials.gov/ct2/show/NCT02155972.

[128] https://clinicaltrials.gov/ct2/show/NCT02334644.

[129] NCT02545634, https://clinicaltrials.gov.

[130] ClinicalTrials.gov, Identifier: NCT02469545, https://clinicaltrials.gov.

[131] Z. Asemi, Z. Zare, H. Shakeri, S.-S. Sabihi, and A. Esmaillzadeh, "Effect of multispecies probiotic supplements on metabolic profiles, hs-CRP, and oxidative stress in patients with type 2 diabetes," Annals of Nutrition and Metabolism, vol. 63, no. 1-2, pp. 1-9, 2013.

[132] S. J. Spaiser, T. Culpepper, C. Nieves et al., "Lactobacillus gasseri KS-13, Bifidobacterium bifidum G9-1, and Bifidobacterium longum MM-2 Ingestion induces a less inflammatory cytokine profile and a potentially beneficial shift in gut microbiota in older adults: a randomized, double-blind, placebocontrolled, crossover study," Journal of the American College of Nutrition, vol. 34, no. 6, pp. 459-469, 2015.

[133] M. Naruszewicz, M.-L. Johansson, D. Zapolska-Downar, and H. Bukowska, "Effect of Lactobacillus plantarum 299v on cardiovascular disease risk factors in smokers," American Journal of Clinical Nutrition, vol. 76, no. 6, pp. 1249-1255, 2002.
[134] A. Rehema, T. Kullisaar, K. Seer, K. Reinmann, M. Zilmer, and K. Kilk, "Proteomic proof that a probiotic elevates glutathione level in human serum," Open Life Sciences, vol. 10, no. 1, pp. 193200, 2015.

[135] A. Kato-Kataoka, K. Nishida, M. Takada et al., "Fermented milk containing Lactobacillus casei strain Shirota prevents the onset of physical symptoms in medical students under academic examination stress," Beneficial Microbes, vol. 7, no. 2, pp. 153156, 2016.

[136] M. Hariri, R. Salehi, A. Feizi, M. Mirlohi, R. Ghiasvand, and N. Habibi, "A randomized, double-blind, placebo-controlled, clinical trial on probiotic soy milk and soy milk: effects on epigenetics and oxidative stress in patients with type II diabetes," Genes and Nutrition, vol. 10, article 52, 2015.

[137] K. Schmidt, P. J. Cowen, C. J. Harmer, G. Tzortzis, S. Errington, and P. W. J. Burnet, "Prebiotic intake reduces the waking cortisol response and alters emotional bias in healthy volunteers," Psychopharmacology, vol. 232, no. 10, pp. 1793-1801, 2015.

[138] K. Tillisch, J. Labus, L. Kilpatrick et al., "Consumption of fermented milk product with probiotic modulates brain activity," Gastroenterology, vol. 144, no. 7, pp. 1394-1401.e4, 2013.

[139] A. A. Mohammadi, S. Jazayeri, K. Khosravi-Darani et al., "The effects of probiotics on mental health and hypothalamicpituitary-adrenal axis: a randomized, double-blind, placebocontrolled trial in petrochemical workers," Nutritional Neuroscience, 2015.

[140] T. Ringel-Kulka, J. B. Kotch, E. T. Jensen, E. Savage, and D. J. Weber, "Randomized, double-blind, placebo-controlled study of synbiotic yogurt effect on the health of children," Journal of Pediatrics, vol. 166, no. 6, pp. 1475-1481.e3, 2015.

[141] M. E. R. O’Brien, H. Anderson, E. Kaukel et al., "SRL 172 (killed Mycobacterium vaccae) in addition to standard chemotherapy improves quality of life without affecting survival, in patients with advanced non-small-cell lung cancer: phase III results," Annals of Oncology, vol. 15, no. 6, pp. 906-914, 2004.

[142] V. Lorenzo-Zúñiga, E. Llop, C. Suárez et al., "I.31, a new combination of probiotics, improves irritable bowel syndromerelated quality of life," World Journal of Gastroenterology, vol. 20, no. 26, pp. 8709-8716, 2014.

[143] J.-Y. Lee, S.-H. Chu, J. Y. Jeon et al., "Effects of 12 weeks of probiotic supplementation on quality of life in colorectal cancer survivors: a double-blind, randomized, placebo-controlled trial," Digestive and Liver Disease, vol. 46, no. 12, pp. 1126-1132, 2016.

[144] I.-J. Wang and J.-Y. Wang, "Children with atopic dermatitis show clinical improvement after Lactobacillus exposure," Clinical and Experimental Allergy, vol. 45, no. 4, pp. 779-787, 2015.

[145] A. M. Wood and S. Joseph, “The absence of positive psychological (eudemonic) well-being as a risk factor for depression: a ten year cohort study," Journal of Affective Disorders, vol. 122, no. 3, pp. 213-217, 2010.

[146] R. Dubos, "Human ecology," WHO Chronicle, vol. 23, no. 11, pp. 499-504, 1969.

[147] R. Duobos, R. W. Schaedler, and R. Costello, "Composition, alteration, and effects of the intestinal flora," Federation Proceedings, vol. 22, pp. 1322-1329, 1963.

[148] Report from the Annual Meeting of the Milwaukee Academy of Medicine, "Washing may be harmful, kids," Milwaukee Journal, p. $1,1973$.

[149] A. C. Logan, M. A. Katzman, and V. Balanzá-Martínez, "Natural environments, ancestral diets, and microbial ecology: is there a 
modern 'paleo-deficit disorder'? Part II," Journal of Physiological Anthropology, vol. 34, no. 1, article 9, 2015.

[150] C. E. West, M. C. Jenmalm, A. L. Kozyrskyj, and S. L. Prescott, "Probiotics for treatment and primary prevention of allergic diseases and asthma: looking back and moving forward," Expert Review of Clinical Immunology, vol. 12, no. 6, pp. 625-639, 2016.

[151] S. Whitmee, A. Haines, C. Beyrer et al., "Safeguarding human health in the Anthropocene epoch: report of The Rockefeller Foundation-Lancet Commission on planetary health," The Lancet, vol. 386, no. 10007, pp. 1973-2028, 2015.

[152] A. Mosca, M. Leclerc, and J. P. Hugot, "Gut microbiota diversity and human diseases: should we reintroduce key predators in our ecosystem?" Frontiers in Microbiology, vol. 7, article 455, 2016.

[153] R. J. Mitchell, E. A. Richardson, N. K. Shortt, and J. R. Pearce, "Neighborhood environments and socioeconomic inequalities in mental well-being," American Journal of Preventive Medicine, vol. 49, no. 1, pp. 80-84, 2015.

[154] A. C. Logan and E. M. Selhub, "Vis Medicatrix naturae: does nature 'minister to the mind'?" BioPsychoSocial Medicine, vol. 6, article 11, 2012.

[155] R. A. Fuller, K. N. Irvine, P. Devine-Wright, P. H. Warren, and K. J. Gaston, "Psychological benefits of greenspace increase with biodiversity," Biology Letters, vol. 3, no. 4, pp. 390-394, 2007.

[156] G. W. Luck, P. Davidson, D. Boxall, and L. Smallbone, "Relations between urban bird and plant communities and human wellbeing and connection to nature," Conservation Biology, vol. 25, no. 4, pp. 816-826, 2011.

[157] A. Shwartz, A. Turbé, L. Simon, and R. Julliard, "Enhancing urban biodiversity and its influence on city-dwellers: an experiment," Biological Conservation, vol. 171, pp. 82-90, 2014.

[158] A. Muratet, P. Pellegrini, A.-B. Dufour, T. Arrif, and F. Chiron, "Perception and knowledge of plant diversity among urban park users," Landscape and Urban Planning, vol. 137, pp. 95-106, 2015.

[159] G. Carrus, M. Scopelliti, R. Lafortezza et al., "Go greener, feel better? The positive effects of biodiversity on the wellbeing of individuals visiting urban and peri-urban green areas," Landscape and Urban Planning, vol. 134, pp. 221-228, 2015.

[160] B. W. Wheeler, R. Lovell, S. L. Higgins et al., "Beyond greenspace: an ecological study of population general health and indicators of natural environment type and quality," International Journal of Health Geographics, vol. 14, article 17, 2015.

[161] H. Duarte-Tagles, A. Salinas-Rodríguez, Á. J. Idrovo, A. Búrquez, and V. Corral-Verdugo, "Biodiversity and depressive symptoms in mexican adults: exploration of beneficial environmental effects," Biomedica, vol. 35, no. 3, pp. 46-57, 2015.

[162] J. W. Leff, P. Del Tredici, W. E. Friedman, and N. Fierer, "Spatial structuring of bacterial communities within individual Ginkgo biloba trees," Environmental Microbiology, vol. 17, no. 7, pp. 2352-2361, 2015.

[163] G. Rastogi, G. L. Coaker, and J. H. J. Leveau, "New insights into the structure and function of phyllosphere microbiota through high-throughput molecular approaches," FEMS Microbiology Letters, vol. 348, no. 1, pp. 1-10, 2013.

[164] M. R. Lambais, A. R. Lucheta, and D. E. Crowley, "Bacterial community assemblages associated with the phyllosphere, dermosphere, and rhizosphere of tree species of the atlantic forest are host taxon dependent," Microbial Ecology, vol. 68, no. 3, pp. 567-574, 2014.

[165] M. C. Horner-Devine, K. M. Carney, and B. J. M. Bohannan, "An ecological perspective on bacterial biodiversity," Proceedings of the Royal Society B: Biological Sciences, vol. 271, no. 1535, pp. 113$122,2004$.
[166] A. M. Womack, B. J. M. Bohannan, and J. L. Green, "Biodiversity and biogeography of the atmosphere," Philosophical Transactions of the Royal Society B: Biological Sciences, vol. 365, no. 1558, pp. 3645-3653, 2010.

[167] B. T. Shaffer and B. Lighthart, "Survey of culturable airborne bacteria at four diverse locations in Oregon: urban, rural, forest, and coastal," Microbial Ecology, vol. 34, no. 3, pp. 167-177, 1997.

[168] R. M. Bowers, S. McLetchie, R. Knight, and N. Fierer, "Spatial variability in airborne bacterial communities across land-use types and their relationship to the bacterial communities of potential source environments," ISME Journal, vol. 5, no. 4, pp. 601-612, 2011.

[169] J. S. Seifried, A. Wichels, and G. Gerdts, "Spatial distribution of marine airborne bacterial communities," MicrobiologyOpen, vol. 4, no. 3, pp. 475-490, 2015.

[170] L. von Hertzen, B. Beutler, J. Bienenstock et al., "Helsinki alert of biodiversity and health," Annals of Medicine, vol. 47, no. 3, pp. 218-225, 2015.

[171] T. Haahtela, S. Holgate, R. Pawankar et al., "The biodiversity hypothesis and allergic disease: world allergy organization position statement," World Allergy Organization Journal, vol. 6, no. 1, article 3, 2013.

[172] G. A. Rook, "Regulation of the immune system by biodiversity from the natural environment: an ecosystem service essential to health," Proceedings of the National Academy of Sciences of the United States of America, vol. 110, no. 46, pp. 18360-18367, 2013.

[173] J. M. Craig, A. C. Logan, and S. L. Prescott, "Natural environments, nature relatedness and the ecological theater: connecting satellites and sequencing to shinrin-yoku," Journal of Physiological Anthropology, vol. 5, article 1, 2016.

[174] World Health Organization Press Release, Report on Health and Biodiversity Demonstrates Human Health Benefits from Protecting Biodiversity, http://www.unep.org/newscentre/default.aspx? DocumentID=2818\&ArticleID=11139.

[175] T. W. McDade, J. B. Borja, L. S. Adair, and C. Kuzawa, "Depressive symptoms are not associated with inflammation in younger and older adults in the Philippines," Evolution, Medicine, and Public Health, vol. 2013, no. 1, pp. 18-23, 2013.

[176] N. Segata, "Gut microbiome: westernization and the disappearance of intestinal diversity," Current Biology, vol. 25, no. 14, pp. R611-R613, 2015.

[177] D. Hospodsky, A. J. Pickering, T. R. Julian et al., "Hand bacterial communities vary across two different human populations," Microbiology (United Kingdom), vol. 160, no. 6, pp. 1144-1152, 2014.

[178] E. F. Delong, "Alien invasions and gut 'island biogeography", Cell, vol. 159, no. 2, pp. 233-235, 2014.

[179] H. Seedorf, N. W. Griffin, V. K. Ridaura et al., "Bacteria from diverse habitats colonize and compete in the mouse gut," Cell, vol. 159, no. 2, pp. 253-266, 2014.

[180] H. Bezerra de Araujo Filho, M. Silva Carmo-Rodrigues, C. Santos Mello et al., "Children living near a sanitary landfill have increased breath methane and Methanobrevibacter smithii in their intestinal microbiota," Archaea, vol. 2014, Article ID 576249, 6 pages, 2014.

[181] A. D. McEachran, B. R. Blackwell, J. D. Hanson et al., "Antibiotics, bacteria, and antibiotic resistance genes: aerial transport from cattle feed yards via particulate matter," Environmental Health Perspectives, vol. 123, no. 4, pp. 337-343, 2015.

[182] J. F. Ruiz-Calderon, H. Cavallin, S. J. Song et al., "Walls talk: microbial biogeography of homes spanning urbanization," Science Advances, vol. 2, no. 2, Article ID e1501061, 2016. 
[183] B. Hesselmar, A. Hicke-Roberts, and G. Wennergren, "Allergy in children in hand versus machine dishwashing," Pediatrics, vol. 135, no. 3, pp. e590-e597, 2015.

[184] E. Avershina, A. Ravi, O. Storrø, T. Øien, R. Johnsen, and K. Rudi, "Potential association of vacuum cleaning frequency with an altered gut microbiota in pregnant women and their 2-yearold children," Microbiome, vol. 3, no. 1, 2015.

[185] S. Ying, D.-N. Zeng, L. Chi et al., "The influence of age and gender on skin-associated microbial communities in urban and rural human populations," PLoS ONE, vol. 10, no. 10, Article ID e0141842, 2015.

[186] I. Hanski, L. von Hertzen, N. Fyhrquist et al., "Environmental biodiversity, human microbiota, and allergy are interrelated," Proceedings of the National Academy of Sciences of the United States of America, vol. 109, no. 21, pp. 8334-8339, 2012.

[187] L. Ruokolainen, L. von Hertzen, N. Fyhrquist et al., "Green areas around homes reduce atopic sensitization in children," Allergy, vol. 70, no. 2, pp. 195-202, 2015.

[188] N. Fyhrquist, L. Ruokolainen, A. Suomalainen et al., "Acinetobacter species in the skin microbiota protect against allergic sensitization and inflammation," Journal of Allergy and Clinical Immunology, vol. 134, no. 6, pp. 1301-1309.e11, 2014.

[189] T. Nakatsuji, H.-I. Chiang, S. B. Jiang, H. Nagarajan, K. Zengler, and R. L. Gallo, "The microbiome extends to subepidermal compartments of normal skin," Nature Communications, vol. 4, article 1431, 2013.

[190] M. L. Conrad, R. Ferstl, R. Teich et al., "Maternal TLR signaling is required for prenatal asthma protection by the nonpathogenic microbe Acinetobacter lwoffii F78," The Journal of Experimental Medicine, vol. 206, no. 13, pp. 2869-2877, 2009.

[191] B. W. Jin, H. Saito, and Z. Yoshii, "Environmental mycobacteria in Korea. I. Distribution of the organisms," Microbiology and Immunology, vol. 28, no. 6, pp. 667-677, 1984.

[192] D. M. Matthews and S. M. Jenks, "Ingestion of Mycobacterium vaccae decreases anxiety-related behavior and improves learning in mice," Behavioural Processes, vol. 96, pp. 27-35, 2013.

[193] C. A. Lowry, J. H. Hollis, A. de Vries et al., "Identification of an immune-responsive mesolimbocortical serotonergic system: potential role in regulation of emotional behavior," Neuroscience, vol. 146, no. 2, pp. 756-772, 2007.

[194] P. H. Siebler, J. H. Fox, J. E. Hassell, and C. A. Lowry, "Immunization with the immunoregulatory saprophytic bacterium Mycobacterium vaccae," in Proceedings of the Abstracts of the 24th Annual Meeting of the International Behavioral Neuroscience Society, p. 82, Victoria, Canada, July 2015.

[195] C. A. Lowry, "An immunization strategy for prevention of stress-related neuropsychiatric disease," in Proceedings of the Abstracts of the 24th Annual Meeting of the International Behavioral Neuroscience Society, pp. 173-174, Victoria, Canada, July 2015.

[196] K. J. Locey and J. T. Lennon, "Scaling laws predict global microbial diversity," Proceedings of the National Academy of Sciences, vol. 113, no. 21, pp. 5970-5975, 2016.

[197] G. H. Donovan, D. T. Butry, Y. L. Michael et al., "The relationship between trees and human health: evidence from the spread of the emerald ash borer," American Journal of Preventive Medicine, vol. 44, no. 2, pp. 139-145, 2013.

[198] G. H. Donovan, Y. L. Michael, D. Gatziolis, J. P. Prestemon, and E. A. Whitsel, "Is tree loss associated with cardiovasculardisease risk in the Women's Health Initiative? A natural experiment," Health \& Place, vol. 36, pp. 1-7, 2015.
[199] B. A. Jones, "Work more and play less? Time use impacts of changing ecosystem services: the case of the invasive emerald ash borer," Ecological Economics, vol. 124, pp. 49-58, 2016.

[200] W. J. van der Steen and P. J. Thung, Faces of Medicine: A Philosophical Study, Kluwer Academic, Dordrecht, The Netherlands, 1988.

[201] G. Falony, M. Joossens, S. Vieira-Silva et al., "Population-level analysis of gut microbiome variation," Science, vol. 352, no. 6285, pp. 560-564, 2016.

[202] F. Shanahan, "Separating the microbiome from the hyperbolome," Genome Medicine, vol. 7, article 17, 2015.

[203] S. Fiorucci and E. Distrutti, "Bile acid-activated receptors, intestinal microbiota, and the treatment of metabolic disorders," Trends in Molecular Medicine, vol. 21, no. 11, pp. 702-714, 2015.

[204] M.-Q. Xu, H.-L. Cao, W.-Q. Wang et al., "Fecal microbiota transplantation broadening its application beyond intestinal disorders," World Journal of Gastroenterology, vol. 21, no. 1, pp. 102-111, 2015.

[205] A. L. Byrd and J. A. Segre, "Infectious disease. Adapting Koch's postulates," Science, vol. 351, pp. 224-226, 2016.

[206] A. L. Byrd and J. A. Segre, "Integrating host gene expression and the microbiome to explore disease pathogenesis," Genome Biology, vol. 16, article 70, 2015.

[207] M. Palau-Rodriguez, S. Tulipani, M. I. Queipo-Ortuño, M. Urpi-Sarda, F. J. Tinahones, and C. Andres-Lacueva, "Metabolomic insights into the intricate gut microbial-host interaction in the development of obesity and type 2 diabetes," Frontiers in Microbiology, vol. 6, article 1151, 2015.

[208] H. Li, J. He, and W. Jia, "The influence of gut microbiota on drug metabolism and toxicity," Expert Opinion on Drug Metabolism and Toxicology, vol. 12, no. 1, pp. 31-40, 2016.

[209] S. Dash, G. Clarke, M. Berk, and F. N. Jacka, "The gut microbiome and diet in psychiatry: focus on depression," Current Opinion in Psychiatry, vol. 28, no. 1, pp. 1-6, 2015.

[210] M. M. Koller, N. Maeda, P. J. Scarpace, and M. G. HumphreysBeher, "Desipramine changes salivary gland function, oral microbiota, and oral health in rats," European Journal of Pharmacology, vol. 408, no. 1, pp. 91-98, 2000.

[211] E. Jensen-Otsu and G. L. Austin, "Antidepressant use is associated with increased energy intake and similar levels of physical activity," Nutrients, vol. 7, no. 11, pp. 9662-9671, 2015.

[212] M. Yassour, M. Y. Lim, H. S. Yun et al., "Sub-clinical detection of gut microbial biomarkers of obesity and type 2 diabetes," Genome Medicine, vol. 8, no. 1, article 17, 2016.

[213] S. Louis, R. Tappu, A. Damms-Machado, D. H. Huson, S. C. Bischoff, and M. Covasa, "Characterization of the gut microbial community of obese patients following a weight-loss intervention using whole metagenome shotgun sequencing," PLoS ONE, vol. 11, no. 2, Article ID e0149564, 2016.

[214] M. G. Dominguez-Bello and M. J. Blaser, "Asthma: undoing millions of years of coevolution in early life?" Science Translational Medicine, vol. 7, no. 307, 2015.

[215] A. Barberán, R. R. Dunn, B. J. Reich et al., “The ecology of microscopic life in household dust," Proceedings of the Royal Society B: Biological Sciences, vol. 282, no. 1814, Article ID 20151139, 2015.

[216] C. A. Michael, D. Dominey-Howes, and M. Labbate, "The antimicrobial resistance crisis: causes, consequences, and management," Frontiers in Public Health, vol. 2, article 145, 2014.

[217] E. Sousa, V. Quintino, J. Palhas, A. M. Rodrigues, J. Teixeira, and C. I. Lasmezas, "Can environmental education actions 
change public attitudes? an example using the pond habitat and associated biodiversity," PLoS ONE, vol. 11, no. 5, Article ID e0154440, 2016.

[218] M. Richardson, A. Cormack, L. McRobert, R. Underhill, and C. M. Somers, "30 days wild: development and evaluation of a large-scale nature engagement campaign to improve wellbeing," PLOS ONE, vol. 11, no. 2, Article ID e0149777, 2016.

[219] C. A. Capaldi, H. Passmore, E. K. Nisbet, J. M. Zelenski, and R. L. Dopko, "Flourishing in nature: a review of the benefits of connecting with nature and its application as a wellbeing intervention," International Journal of Wellbeing, vol. 5, no. 4, pp. 1-16, 2015.

[220] V. H. Smith, R. J. Rubinstein, S. Park, L. Kelly, and V. KlepacCeraj, "Microbiology and ecology are vitally important to premedical curricula," Evolution, Medicine, and Public Health, vol. 2015, no. 1, pp. 179-192, 2015.

[221] B. Schaller and N. Sandu, "Clinical medicine, public health and ecological health: a new basis for education and prevention?" Archives of Medical Science, vol. 7, no. 4, pp. 541-545, 2011.

[222] A. Gómez, S. Balsari, J. Nusbaum, A. Heerboth, and J. Lemery, "Perspective: environment, biodiversity, and the education of the physician of the future," Academic Medicine, vol. 88, no. 2, pp. 168-172, 2013.

[223] A. Lodge, "Anthropogenic climate change is here: family physicians must respond to the crisis," Canadian Family Physician, vol. 61, no. 7, pp. 582-583, 2015.

[224] R. J. Dubos, "Medicine as a social science," ArizonaMed, pp. 668-673, 1959. 

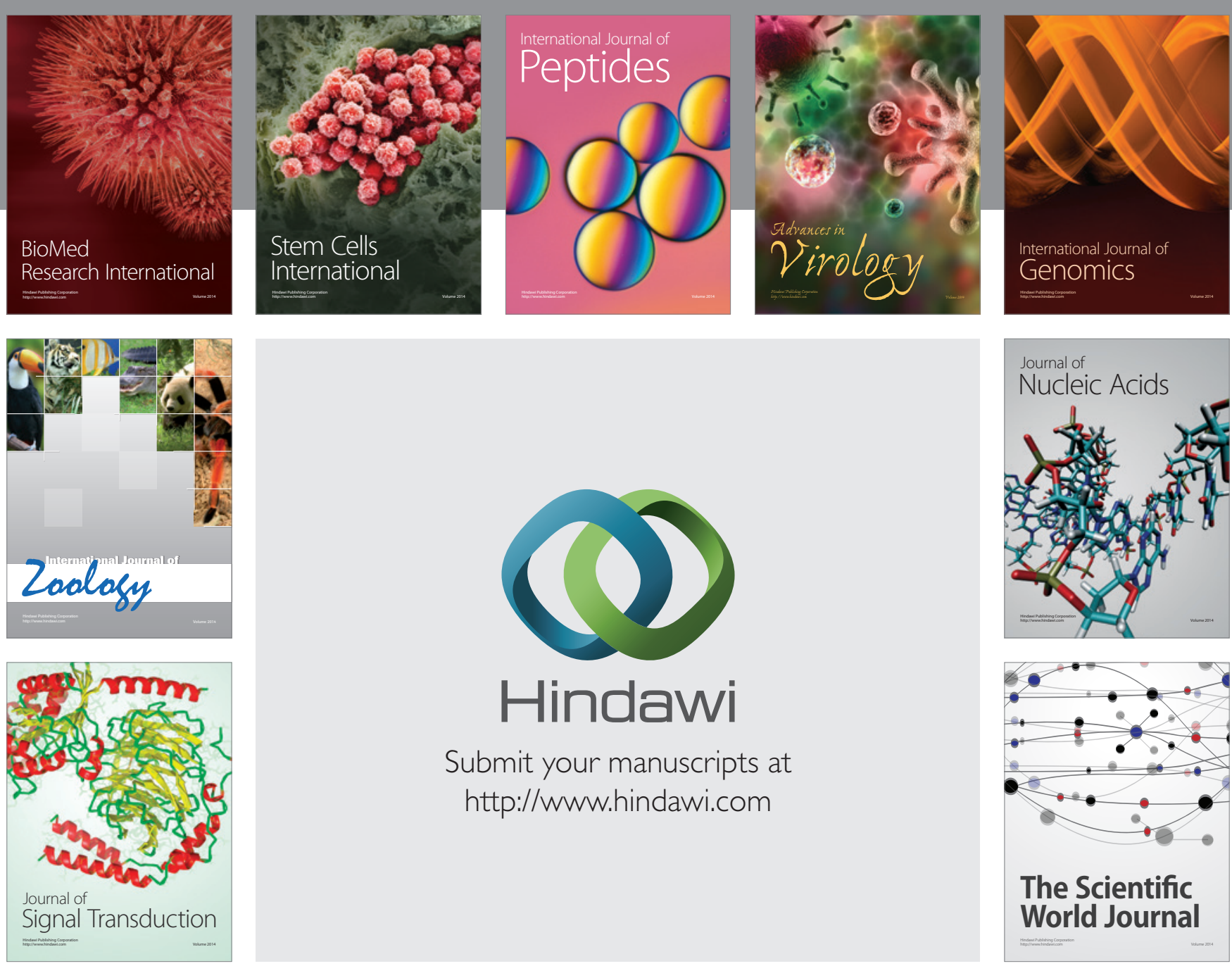

Submit your manuscripts at

http://www.hindawi.com
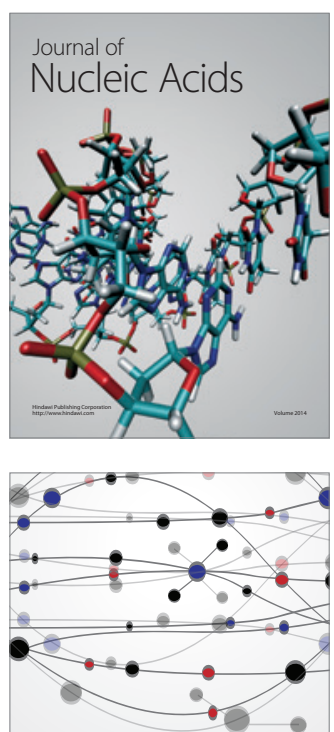

The Scientific World Journal
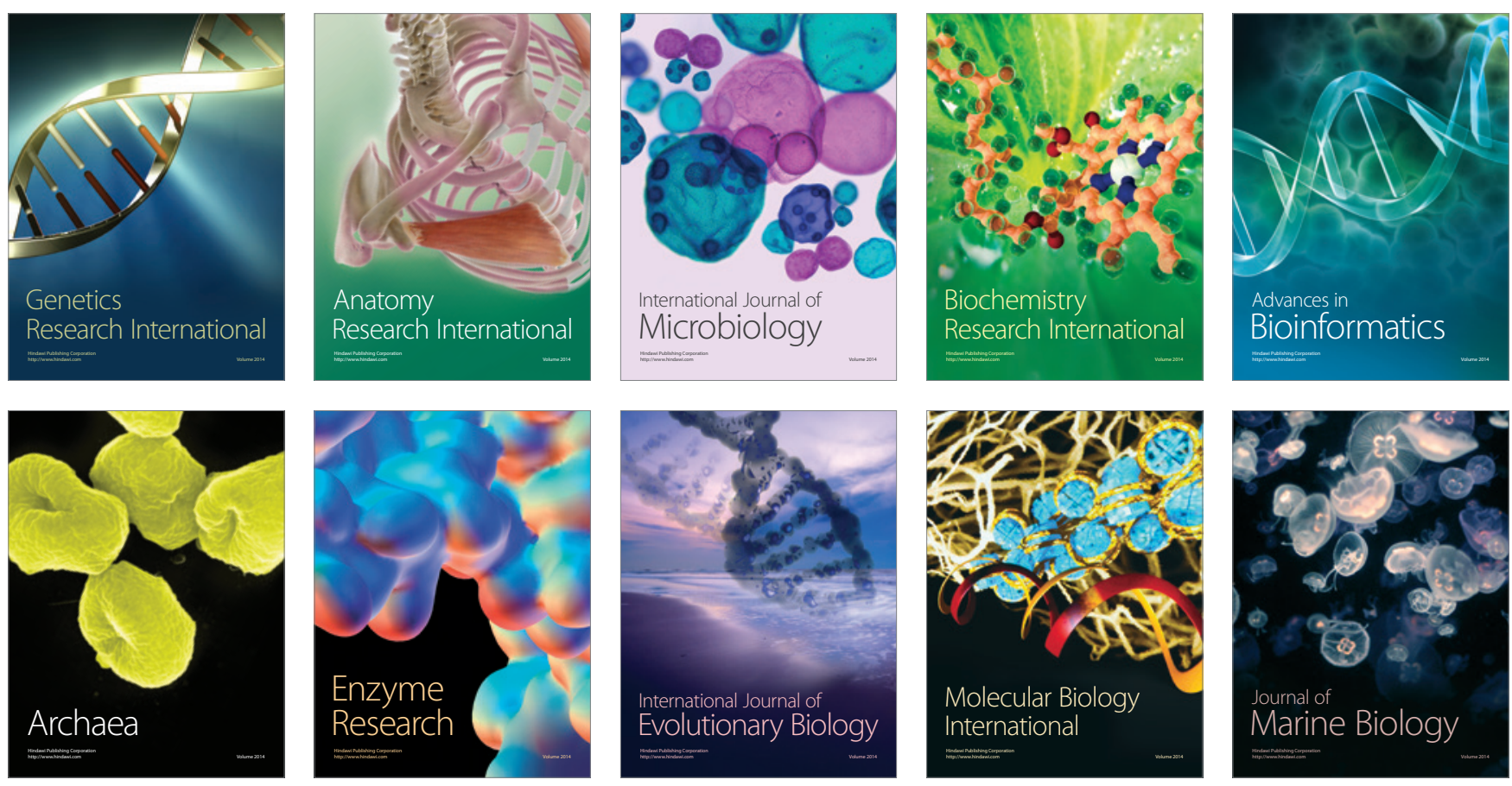